\title{
تقييم اعتبارات التصميم الإيكولوجي المستدام بالبيئة المبنية
}

\author{
د. فرج محمد زكي عبد النبي

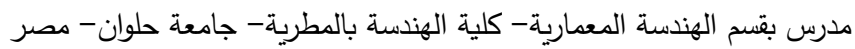

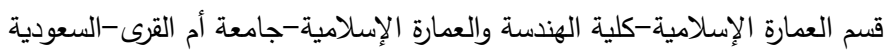 \\ faragzaki2002@yahoo.com
}

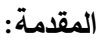

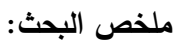

يتطلب العمران الراهن والمستقبلي التكامل بين المنهج

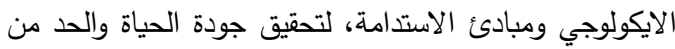

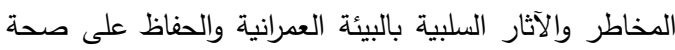

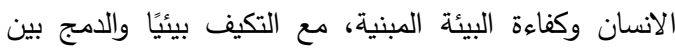

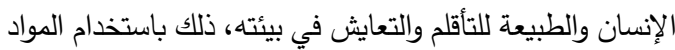

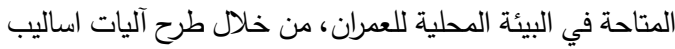

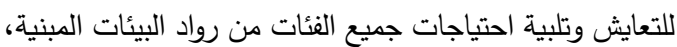

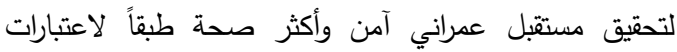
التصميم الإيكولوجي المستدام، (38). 1 مفهوم المنهج الإيكولوجي المستدام. هو علم يهتم بدراسة العلاقات المتبادلة للكائنات الحية مع بيئاتها

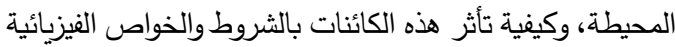

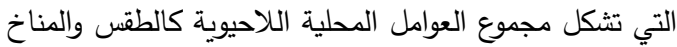
والجيولوجيا، إضافة للكائنات الحية الأخرى التي تثاركها موطنها لإنيا

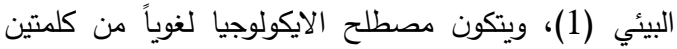

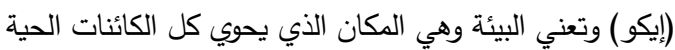

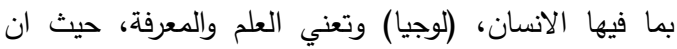
(الأيكولوجي) يعني علم علاقات وتفاعلات الأحياء مع البيئة

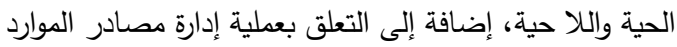

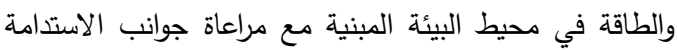

شكل (1) البيئية والاقتصادية والاجتماعية والتشريعية (2).

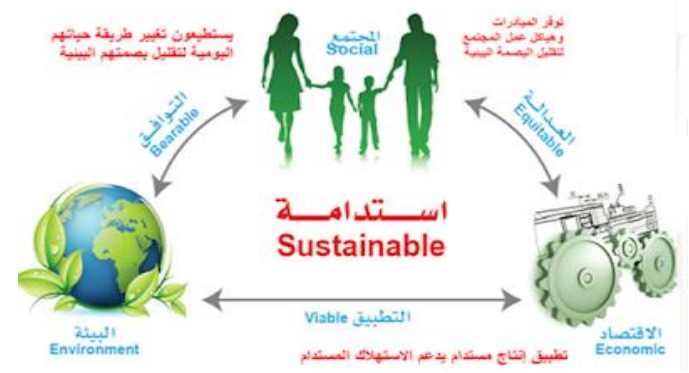

شكل (1) تكامل وتوافق المفهوم الايكولوجي مع جوانب الاستدامة.

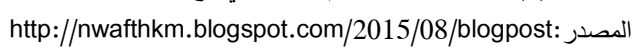

بالنظر الى تعدد المشكلات والقضايا العمرانية نتيجة بعض المتغيرات البيئية وفقدان التتوع والاتزان البيولوجي بالعمدران، ظهرت الحاجة الى توفير علاقة إيجابية بين المباني والبيئة الطبيعية المحيطة، للتقليل من التأثيرات السلبية على البيئة المبنية لتصبح صالحة للعيش وصديقة للإنسان، حيث تمثلت الإثكالية في إغفال الكثير من العمرانيين والمعماريين تطبيق اعتبارات التصميم الأيكولوجي المستدام بالبيئة المبنية، مما أدى الإن

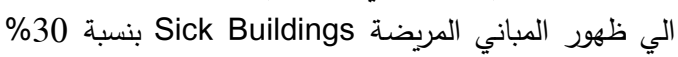
من العمران نتيجة لعدم التكامل الايكولوجي، تضمنت المظاهر السلبية التي تعانى منها البيئة المبنية علي مستوى المباني والغراغات المحيطة، كما تفتقر الأنماط العمرانية والمعمارية الحالية لتحقيق ومبادئ ومعايير الاستدامة الايكولوجية، لذا يهدف البحث لتقييم مدى تطبيق الاعتبارات الايكولوجية من خلال طرح منهجية للتقييم وفق أسس ومعايير علمية، لإيجاد

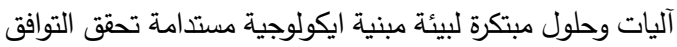
بين حاجات الإنسان والمحددات الطبيعية والبيئية، لتوفير بيئة مبنية صحية لمواجهة القضايا العمرانية والمتغيرات المستقبلية، ويفترض البحث ان التصميم الأيكولوجي المستدام كأحد الاتجاهات الحديثة للفكر العمراني والمعماري يحقق إيجابية العلاقة بين المباني والبيئة الطبيعية، مع تحقيق الإنتاج Production Sustainability المنهج الاستقرائي بالدراسة النظرية، والمنهج التحلية التيلي الاستنباطي والمقارن بالدراسة التحليلية، لدراسة التجارب العالمية وتقييم صحة المنهجية المقترحة، ومن ثم رصد وتحليل النتائج في صورة مقارنات بيانية، والتي اثبتت صحة الفرضية وتحقيق الهدف بتقييم مدى تطبيق المنهجية المقترحة لتحقيق اعتبارات التصميم الايكولوجي لاستدامة البيئة المبنية. الكلمات الدلالية: التصميم الأيكولوجي- البيئة المبنية- العمران المستدام - التغيرات المستقبلية - القضايا العمرانية. 
1-2-1-1خصائص النظام الايكولوجي المستدام.

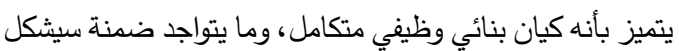

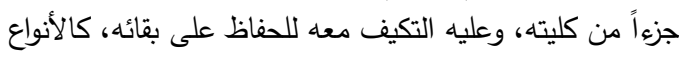

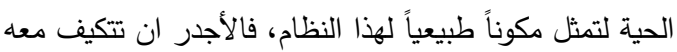

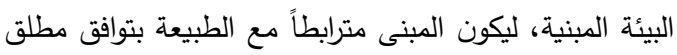

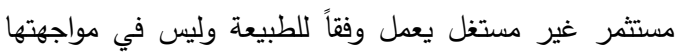

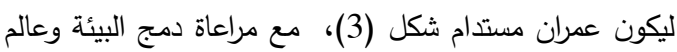
الإنسان والحيوان والنبات في إطار واحد، وطرح نظام نـام بنائي وظيفي متكامل يتمثل في عمليات تدفق الطاقة، وتوزيع الغذاء الغاء

بين مختلف الأنواع الحية بطريقة شاملة (7).

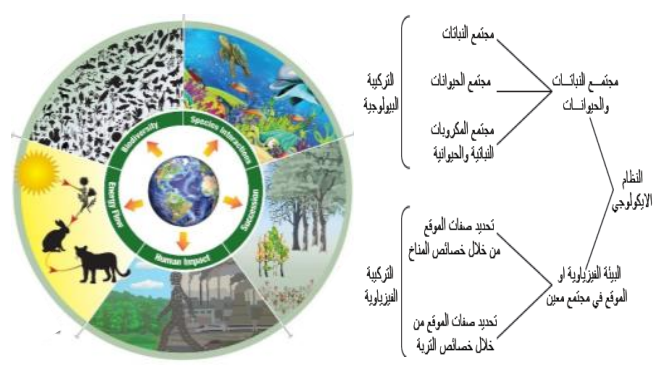

شكل (3) توافق محتويات النظام الايكولوجي المستدام مع مواعاة دمج البيئة

وعالم الإنسان والحيوان والنبات في إطار واحد ليكون عوران مستدام.

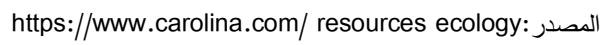

\section{2التصميم الايكولوجي المستدام.}

يعتبر التصميم الايكولوجي منهج تصميمي توقعي، حساس المئي

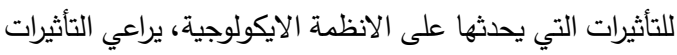

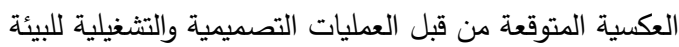

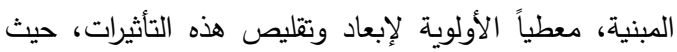

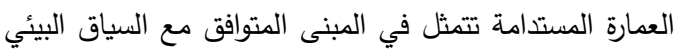

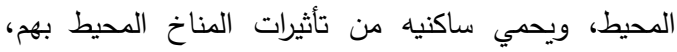

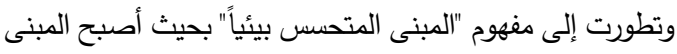

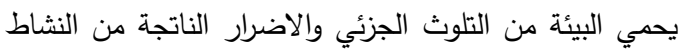
الإنساني، مع الحفاظ على تحقيق راحة المستخدم وحماية الساكنين من تأثيرات العوامل المختلفة، فتحولت سيطرة البئلة البيئة

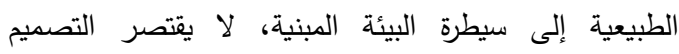

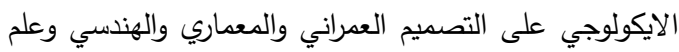
الايكولوجياً، ولكن يضم الإلى الفروع العلمية مثل تخطيط استخدام

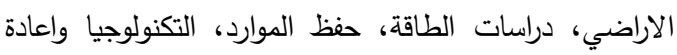

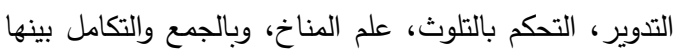
نحصل على منهجية التصميم الايكولوجي المستدام (8).
1-1 1-تعريف المنهج الايكولوجي المستدام.

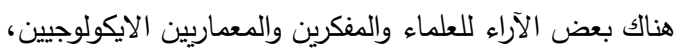
منهم (Yeang) عرف الايكولوجي أنه التفاعل بين الكائنات

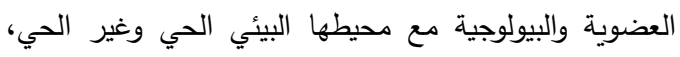

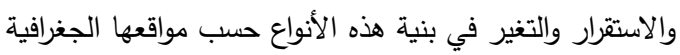

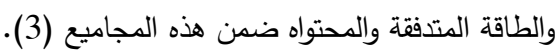

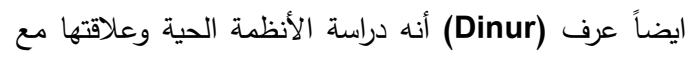

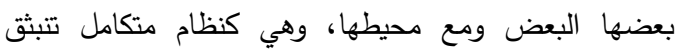
خصائصه من العلاقات بين أجزائه، كل جزء منها كنها يعكس الكل

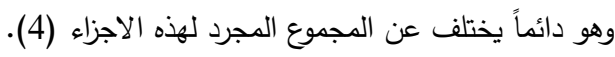

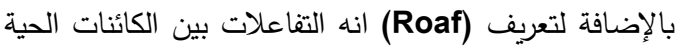

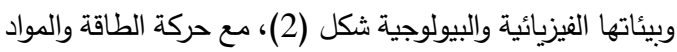

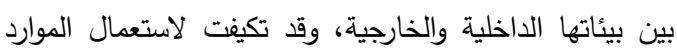

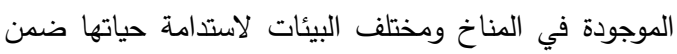

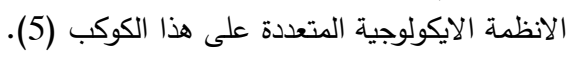

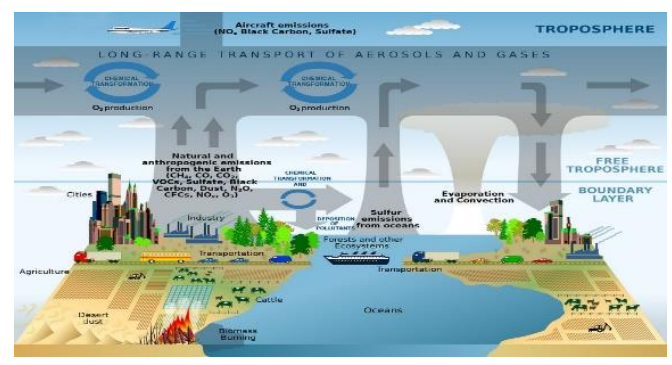

شكل (2) تشمل الايكولوجيا العلاقات التفاعلية بين الانسان، المكان،والبيئة.

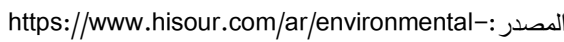

\section{1-2النظام الايكولوجي المستدام.}

إن التفاعل بين مقومات البيئة البيولوجية والفيزيائية خلال وحدة البئية فضائية يطلق عليه "نظام ايكولوجي"، يشمل العلاقات البئية البيئية

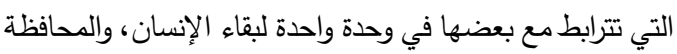

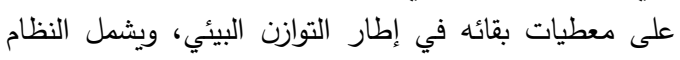

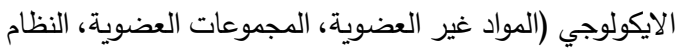

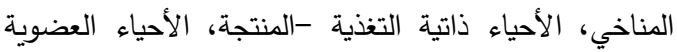

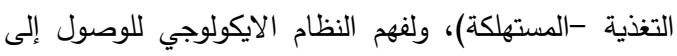

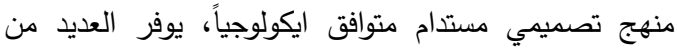

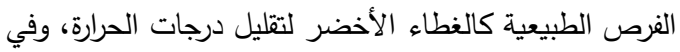
المناطق العمرانية الكثيفة لا يبقى من مكونات النظام الإيكولوجي الإي الإني

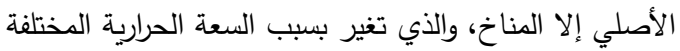

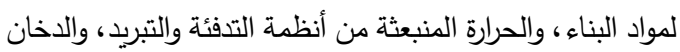
من المصانع والمنازل والسيارات (6). 

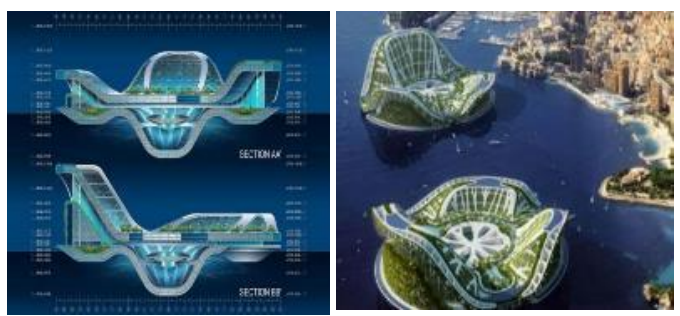

شكل (4) مشروع Lilypad city مدن ايكولوجية عائمة صديقة للبيئة.

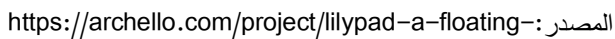

2-2-2-1الموارد الطبيعية الايكولوجية المستدامة.

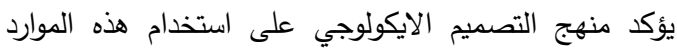

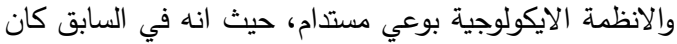

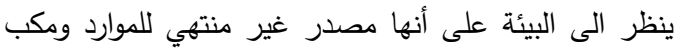

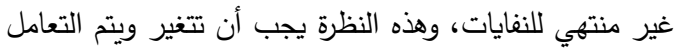

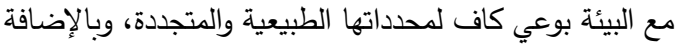

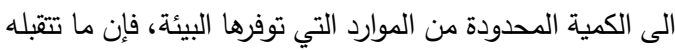

من المخلفات محدود أيضاً ذلك لاستدامة البيئة المبنية (11).

$$
\text { 2-2-2-2 المحيط العمراني الايكولوجي المستدام. }
$$

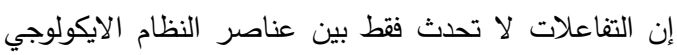

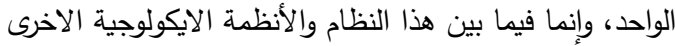

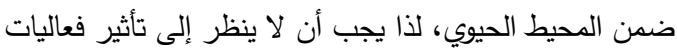

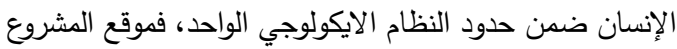

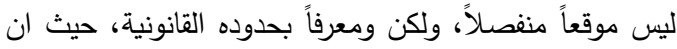

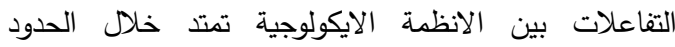

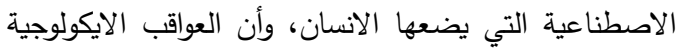

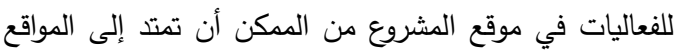

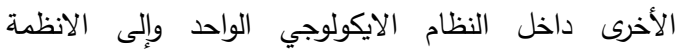

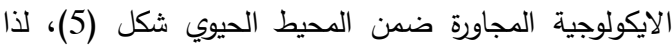
نوضح مقياس هذه التأثيرات الناجمة عن التصميم الجغرافي على النى المحيط الحيوي (41).

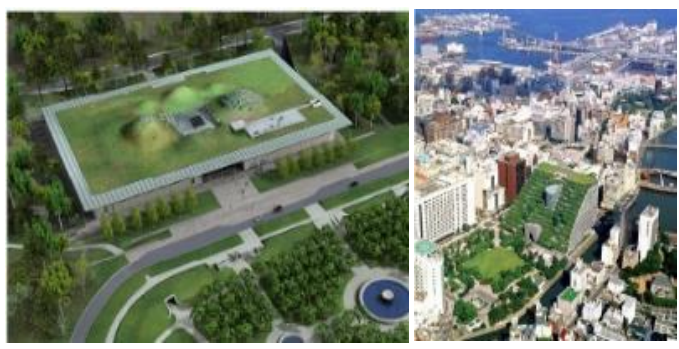

شكل (5) تكامل المبني الانظمة الايكولوجية المجارة ضمن المحيط الحوي.

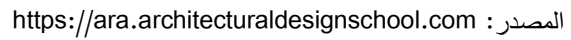

1-201-2 هي ضوابط جديد في العمارة والعمران تهدف إلى إكمال دورة العيته

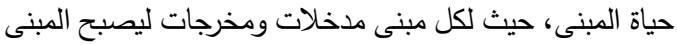

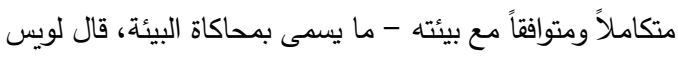

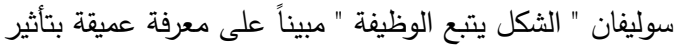

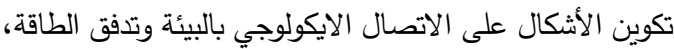

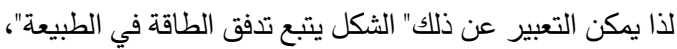

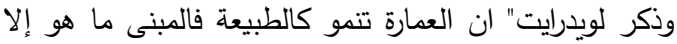

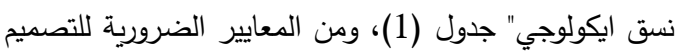

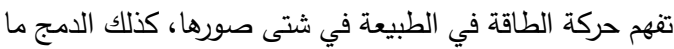

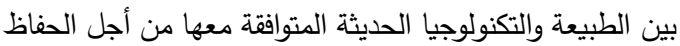
على البيئة، ويوجد عدة معايير نذكرها فيما يلي (9): جدول (1) معايير التصميم الايكولوجي المستدام. المصدر : الباحث.

\begin{tabular}{|c|c|}
\hline معايير التصميم الايكولوجي المستام & \\
\hline كفاءة تصميم وإنثاء عمارة موفرة للطاقة ومطورة في الموادية & 1 \\
\hline فعالية تصميميم بيئة صحية مبنية من حيث على أعلىلى المعاييير & 2 \\
\hline لها تأثير قليل أن لم لم يكن معدوم على البنيل البيئة العمرانية. & 3 \\
\hline تعزيز استخدام وتوظيف مصادر الطاقة المتجددة. & 4 \\
\hline تقليل الطاقة المستعملة واستنزاف المصادر الطبيعية. & 5 \\
\hline حماية وحفظ البيئة النباتية والاحيائية في الموقع. & 6 \\
\hline $\begin{array}{c}\text { الاستفادة من مصاقة البيئة بالمناخ الطبيعية } \\
\text { الطبية }\end{array}$ & 7 \\
\hline 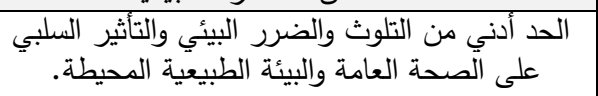 & 8 \\
\hline
\end{tabular}

2-2مقومات التصميم الايكولوجي المستدام: يرى المعماريين أن الناتج النهائي للعمليات التصميمية هو نظام التمات

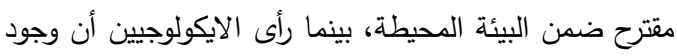

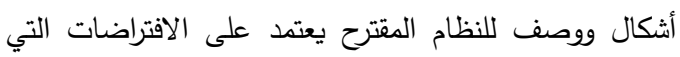

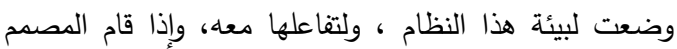

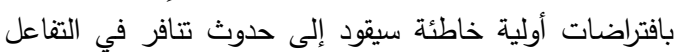
بينهما، حيث إن أي نظام يتأثر بطريقة أو بأخرى بحالة البهات

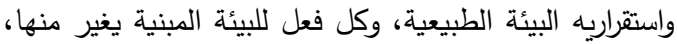

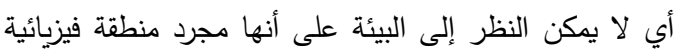

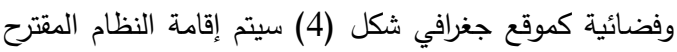

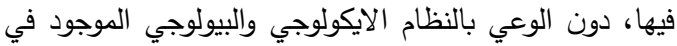

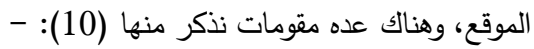


2-2-5-2

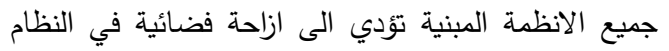

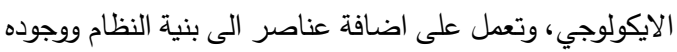

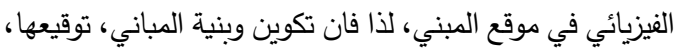

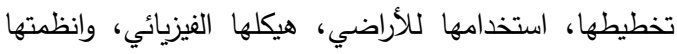

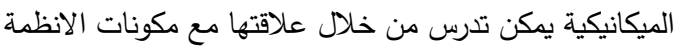

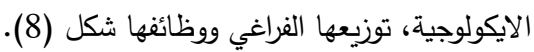

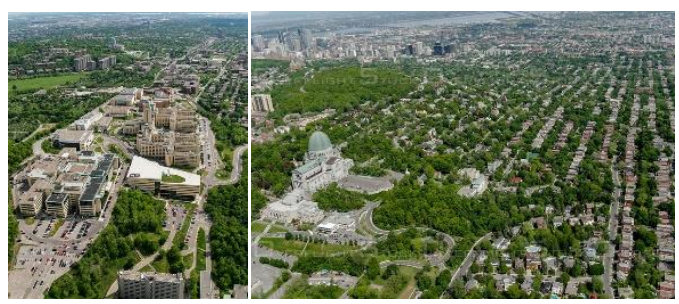

شكل (8) اندماج المباني مع محتويات الانظمة الايكولوجية للفاغات.

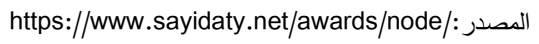

2-2-2-2 ينظر للتصميم ضمن محتواه الايكولوجي الكلي وليس من خلال

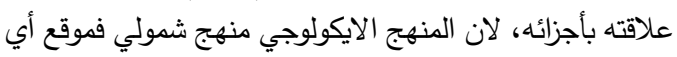

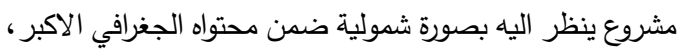

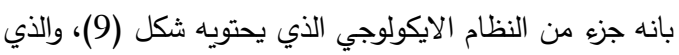

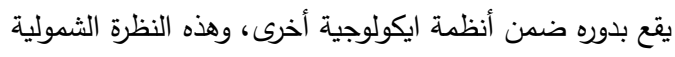

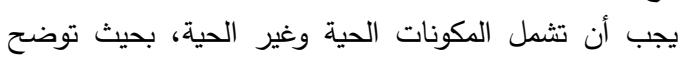

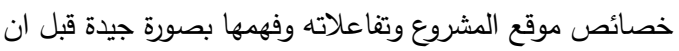

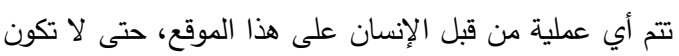

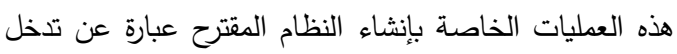
جائر على النظام الايكولوجي لذلك الموقع(36).

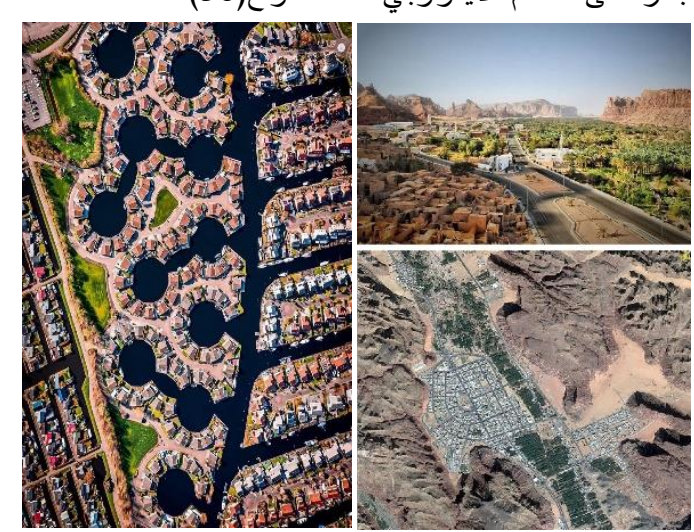

شكل (9) موقع المشروع وتفاعلاته ضمن محتواه العر اني الايكولوجي.

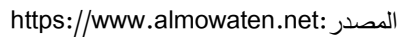

ل2-2-2 خصائص الموقع الايكولوجي المستدام.

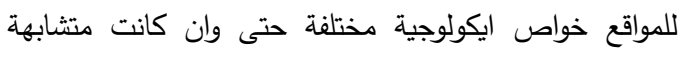
ظاهرياً، عند النظر إلى موقع المشروع على انه الهان سلعة اقتصادية

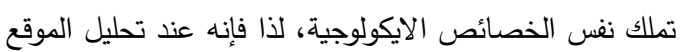

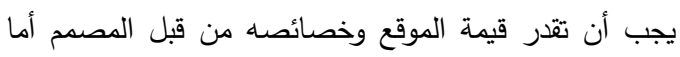
لغرض الحماية والاستفادة منها وترشيد الاستهلاك واست واستخدامها

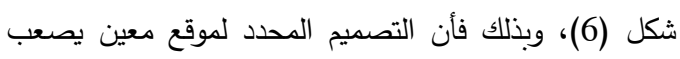

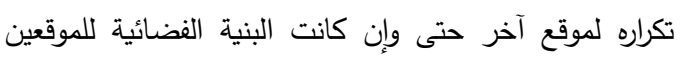
متثابهتين في الخصائص البيئية والعمرانية (41).

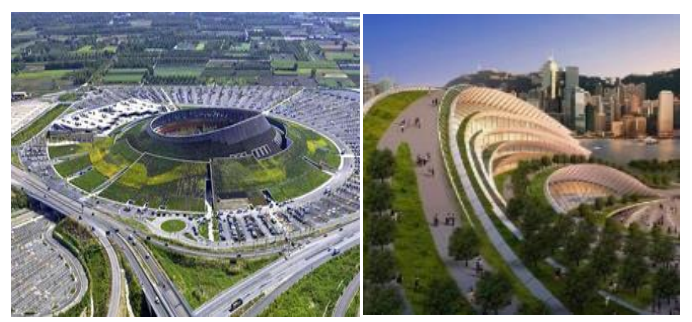

شكل (6) الاستفادة من النظم الايكولوجية للموقع لتوافق المبني مع البيئة.

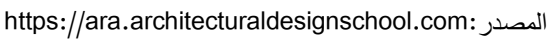

2-2-2-2

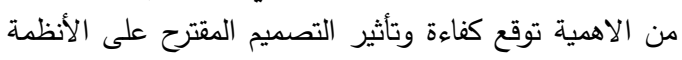

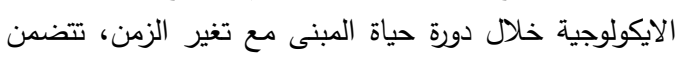
مسؤولية المصممين تأثير الأنظمة المقترحة على الئل البيئة طوال

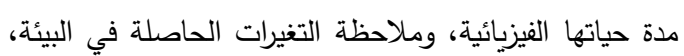

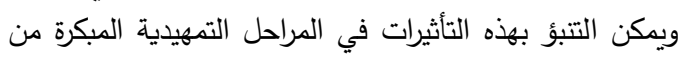

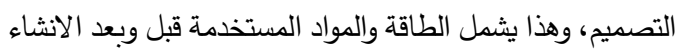

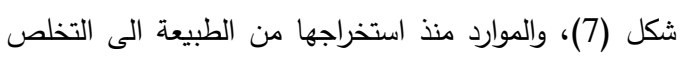

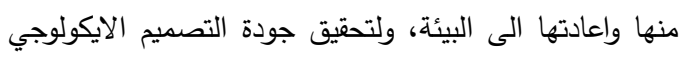

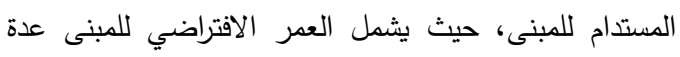

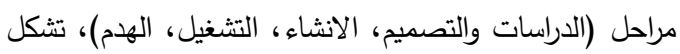

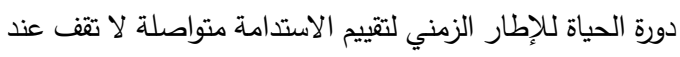
مرحله وهنا تكمن فكره الاستدامة في المباني(38).

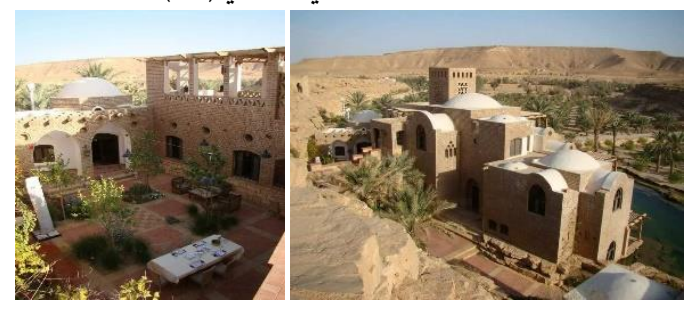

شكل (7) استخدام الخامات والمورد الطبيعية بالمبنى الايكولوجي.

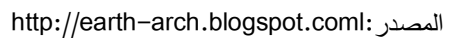


جدول (2) بعض مبادئ التصميم الايكولوجي المستدام. الصصدر : الباحث.

\begin{tabular}{|c|c|c|}
\hline \multicolumn{3}{|c|}{ مبادئ التصميم الايكولوجي المستدام } \\
\hline تحديد ألممارسات التصميمية & جغرافيا المكان & \\
\hline القدرة على احياء البيئة المبنية & التوافق البيئي & \\
\hline المنتجات العرضية غذاء لآخر & التكامل الطبيعي & $\frac{\pi}{2}$ \\
\hline مواد قابلة للتدوير والتوظيف & التأثير البيئي & 高 \\
\hline العادات والتقاليد الدجتمعية & طبيعة المجتمع & \\
\hline التوافق مع الطابع العمراني & المحيط العمراني & \\
\hline الاستفادة من مصادره الطبيعية & علاقة البيئة بالمناخ & \\
\hline حركة الثمس واتجاه الرياح & التكوين العمراني & \\
\hline تحقيق الراحة الحرارية للفضاء & التشكيل المعماري & $\overline{3}$ \\
\hline
\end{tabular}

2-3-2 الاستغلال الامثل للموارد: توجد الموارد في الطبيعة

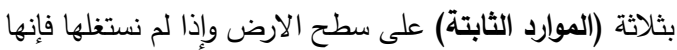

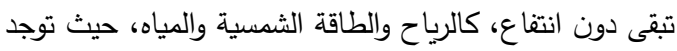
في الطبيعة بوفرة ولكنها أقل الموارد استغلالاً، (الموارد

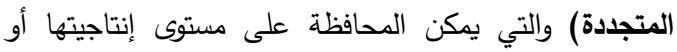

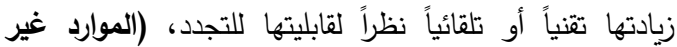
المتجددة) التي يؤدي استغلالها نقص في مخزونها الطبيعي.

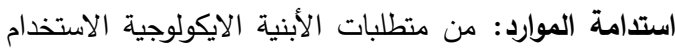

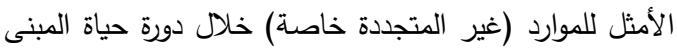

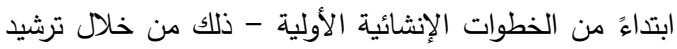
استهلاك موارد عمليات إنشاء وتشغيل المبنى شكل (11)، لإن الان

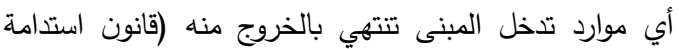

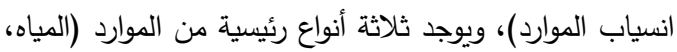

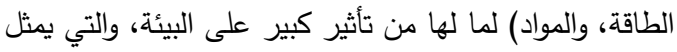

كل منها ضرورة لإنثاء وتثغيل البيئة المبنية (14).

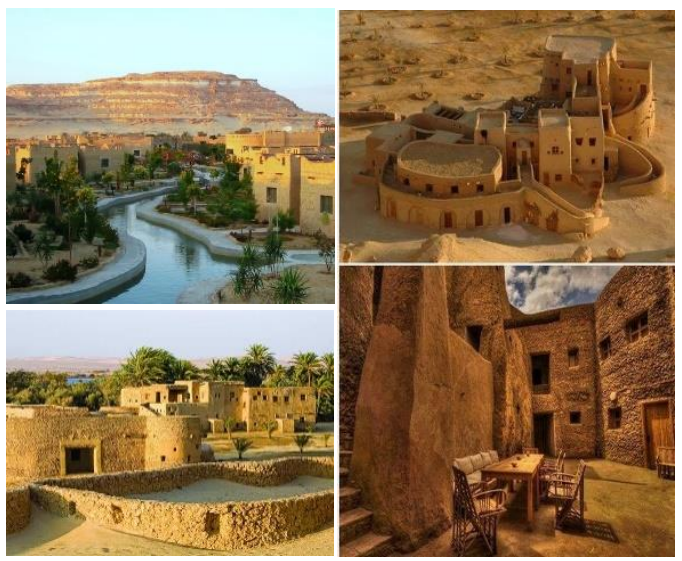

شكل (11) ترشيد استهالك مورد إنشاء وتشغيل المبنى الايكولوجي المستدام.

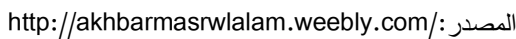

2-2-2 البيئة الطبيعية المستدامة.

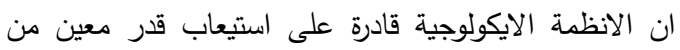

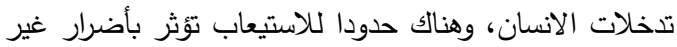

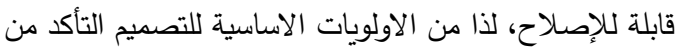

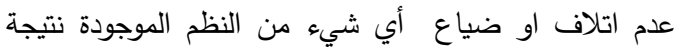

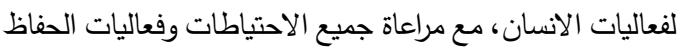

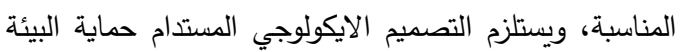

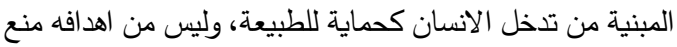
حدوث التغيرات على الانظمة الايكولوجية، ولكن كيفية ربط الانية

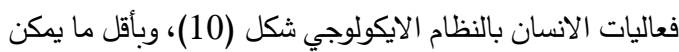

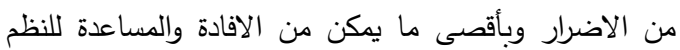

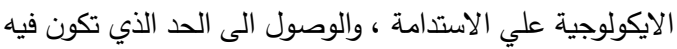

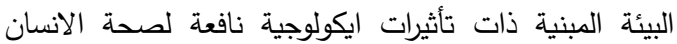
للتعايش مع المتغيرات المستجدة (12).

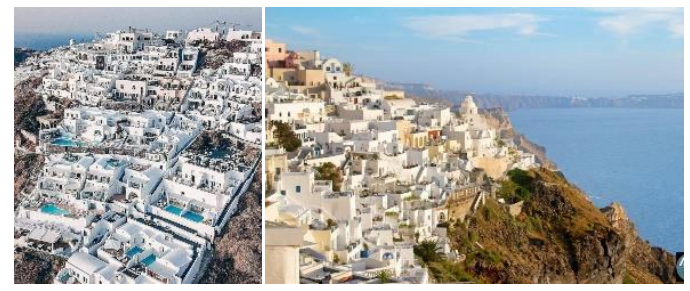
شكل (10) حماية النظم الأيكولوجيةوالبيئة المبنية من تدخل الانسان.

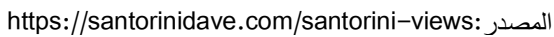
ت2-2مبادئ التصميم الايكولوجي المستدام.

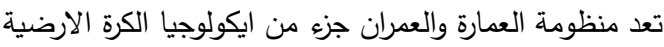
وموطن الحياة الانسانية، فالأبنية الايكولوجية تكون أكثر ارتباطاً

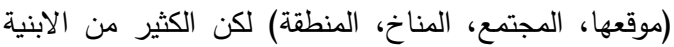

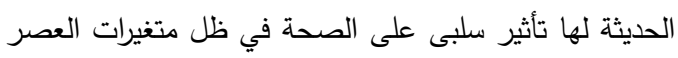

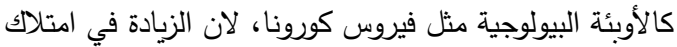

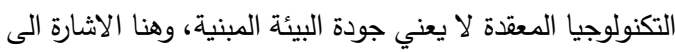

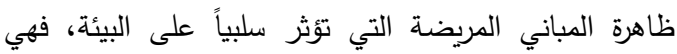
تستهلك اكثر 50\% من الطاقة المستخدمة في البلدان المتطورة

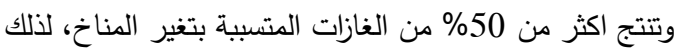

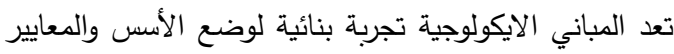

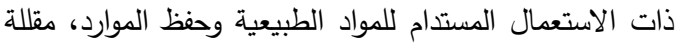

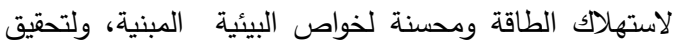

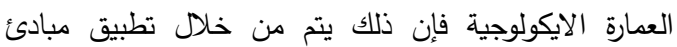

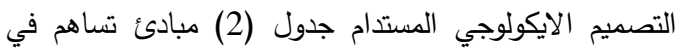
التقليل من التأثير السلبي الناتج من تفاعلات هذا النظام - تقليل استتزاف الموارد والمواد الطبيعية (13). 


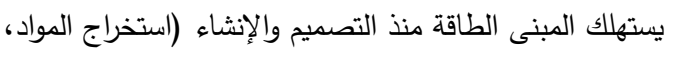

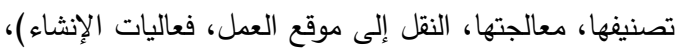

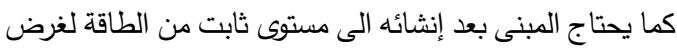

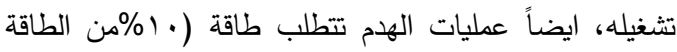

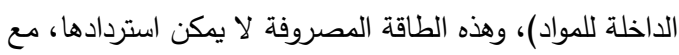

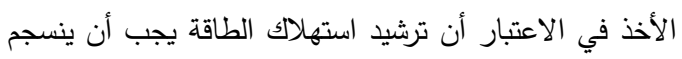
مع متطلبات الإنسان، بمعنى أن ترشيد الطاقة لا يعني تقليل الإنيل

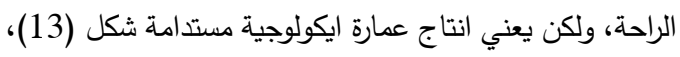

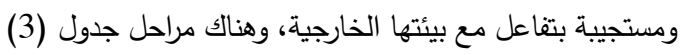
لخفض وترشيد استهلاك الطاقة هي (19):-
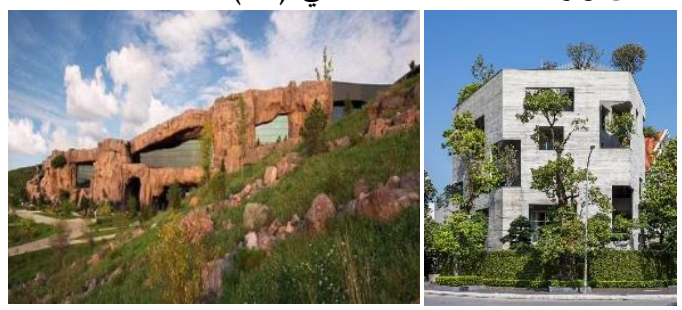

شكل (13) المعالجات الايكولوجية لتوشيد استهلاك الطاقة داخل المبني.

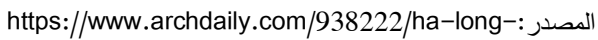
جدول (3) مراحل خفض وترشيد استهلاك الطاقة. المصدر : الباحث.

\begin{tabular}{|c|c|}
\hline \multicolumn{2}{|l|}{ خفض وترشيد استهلاك الطاقة } \\
\hline 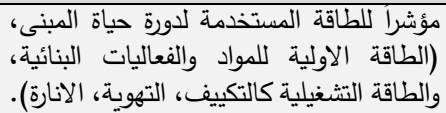 & 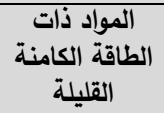 \\
\hline 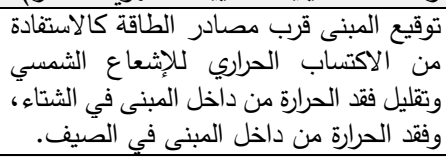 & تلخطيط الموقع \\
\hline 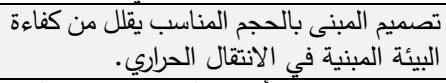 & حجم المبنى \\
\hline فهم واحترام قوة وتأثير الطاقة الثمسية وطاقة التصميم. & أنظمة التبريد \\
\hline 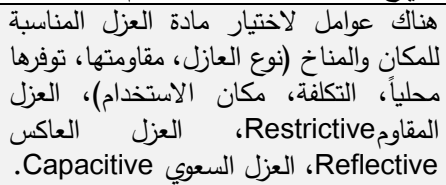 & كفاءة العزل \\
\hline 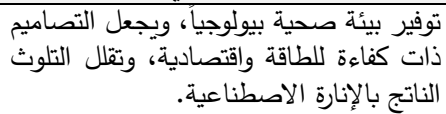 & الطبيعية \\
\hline 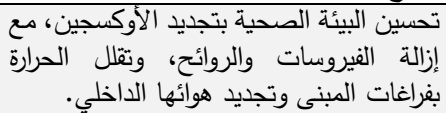 & الطبيعية التهية \\
\hline كفاءة، للاقتصاد بالنارة والتدفئة والتبريد والتهوية ذاتية التشيلية. & كفاءة الطاقة ذاتة \\
\hline
\end{tabular}

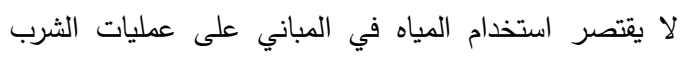

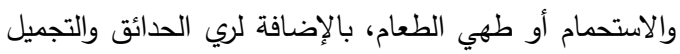

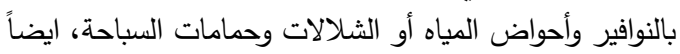

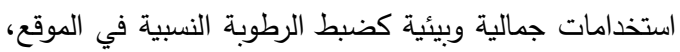

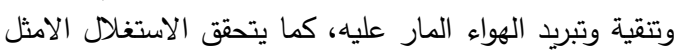

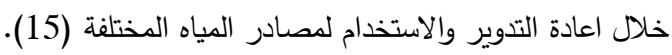

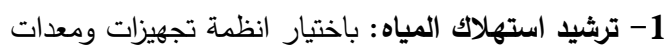

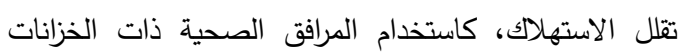
الاقتصادية الصغيرة التي تتحكم في تدفق كمية المياه وتوزيعها،

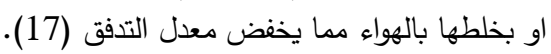
2-2 اعادة تدوير المياه: تصنف المياه المستخدمة في المباني

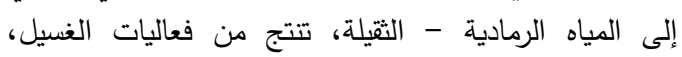

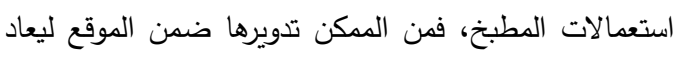

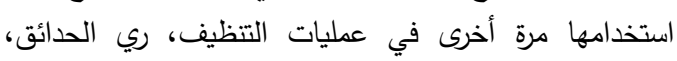

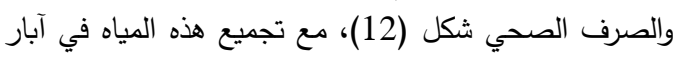

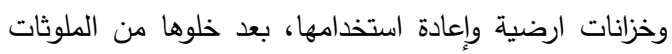

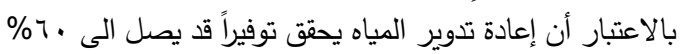

من استهلاك المياه في المبنى (18).

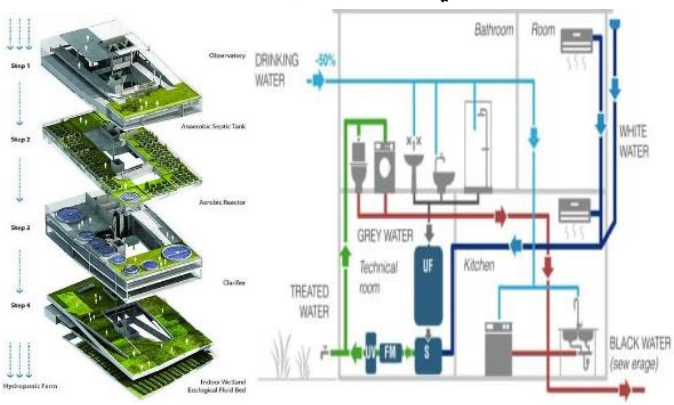

شكل (12) إعادة تنوير واستخدام مورد المياه بالمبنى الايكولوجي.

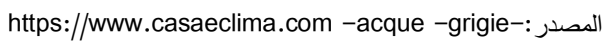

\section{2-3-3 20}

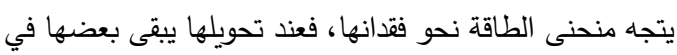

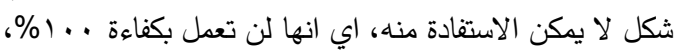

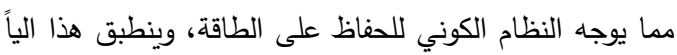

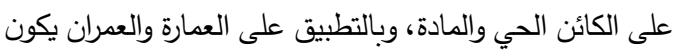

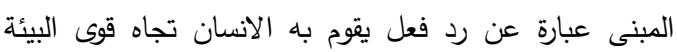

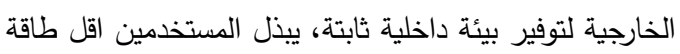

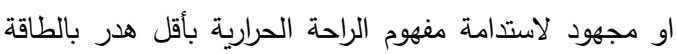
الطبيعية، وذلك من خلال ما يلي (16): - 
3 التصميم الايكولوجي المستدام وقضايا العمران.

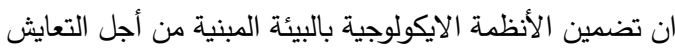

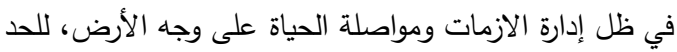
من الآثار السلبية والنظر للبيئة العمرانية ككائن حيوي قابله الإنيل

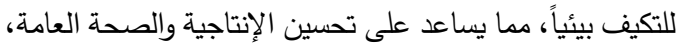

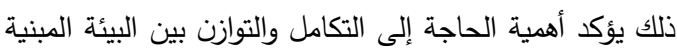

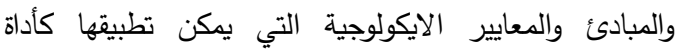

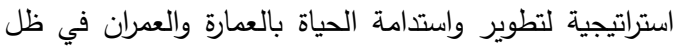

التحديات والمتغيرات المستقبلية (21). 3-1التوافق بين العمارة والعمران.

تعددت المداخل البيئية التي حاولت التوافق بين العمارة والعمران

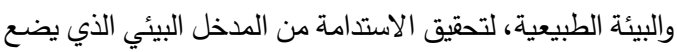

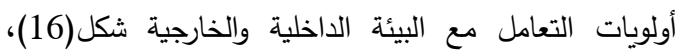
والمدخل الأيكولوجي يحاول الوصول إلى علاقات إيجابية بين

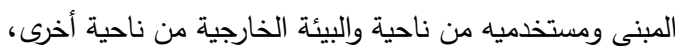
والمدخل الأخضر الذي يتعامل مع المبنى ككائن حي له دانه دورة

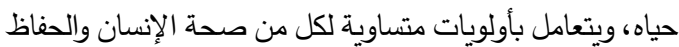
على الموارد والحفاظ البيئي، والمدخل البيو مناخي الذي تولئ تكون أولوياته توظيف العمليات الطبيعية في خدمة راحة مستخدمي ولئي المبنى، لتحقيق التوافق مع تغيرات البيئة الطبيعية من خلال فلئل ترتيب أولويات التعامل مع نوعية المبنى ومستخدميه(22).

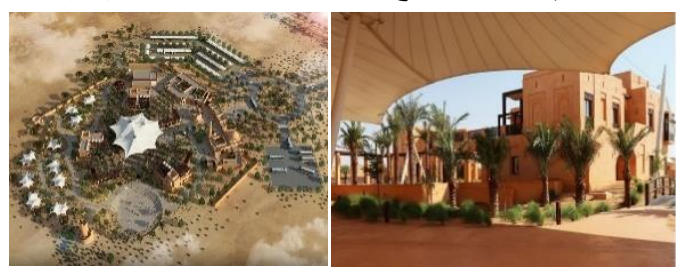

شكل (16) المعالجات البيئية للمباني الايكولوجيةو الموقع العام المستدام.

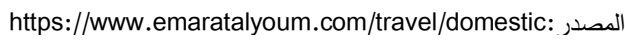

\section{3-2تحقيق البيئة المبنية الصحية.}

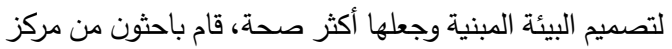
الجينوم في جامعة كاليفورنيا، بالتعاون مع مركز علم الأحياء والبيئة المبنية جامعة أوريغون في الولايات المتحدة، بإجراء

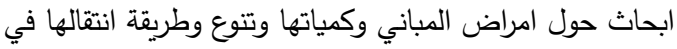

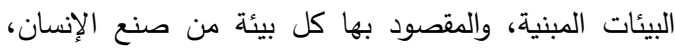

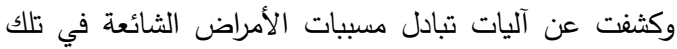

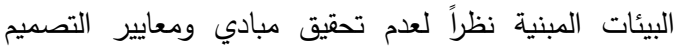

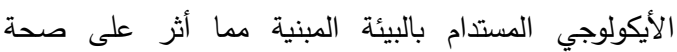
المستخدمين وضعف الكفاءة الانتاجية (23).
ثانياً- الاعتماد على مصادر الطاقة المتجددة.

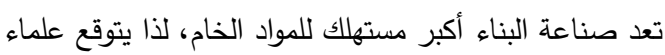

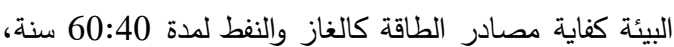

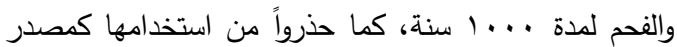
بديل للطاقة، لحدوث أزمة ايكولوجية وآثار سلبية مثل الأمطار

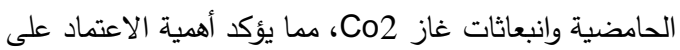

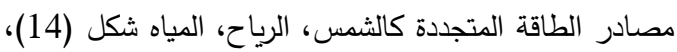
علينا اتباع مبادئ ارشادية كتقليل استهلالك المواد والموارد المياد المياه

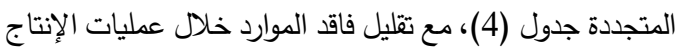
والإنثاء والتشغيل (20).

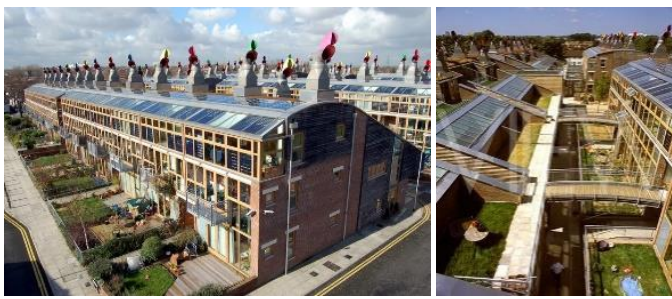

شكل (14) استخدام مصادر الطاقة المتجدة لتحقيق التصميم الايكولوجي.

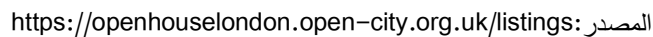

جدول (4) الاعتماد على مصادر الطاقة المتجددة. المصدر : الباحث.

\begin{tabular}{|c|c|}
\hline \multicolumn{2}{|c|}{ الاعتماد على مصادر الطاقة المتجددة } \\
\hline 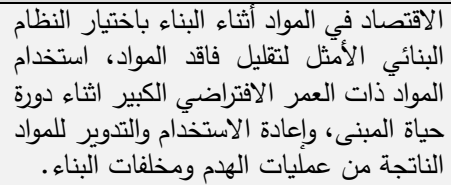 & ترشيد استخدام \\
\hline 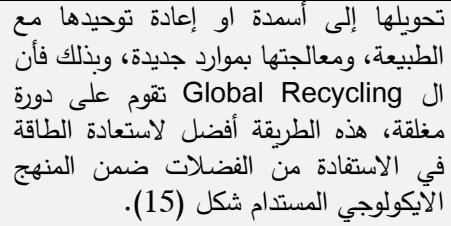 & المواد وادارة تدوير \\
\hline
\end{tabular}

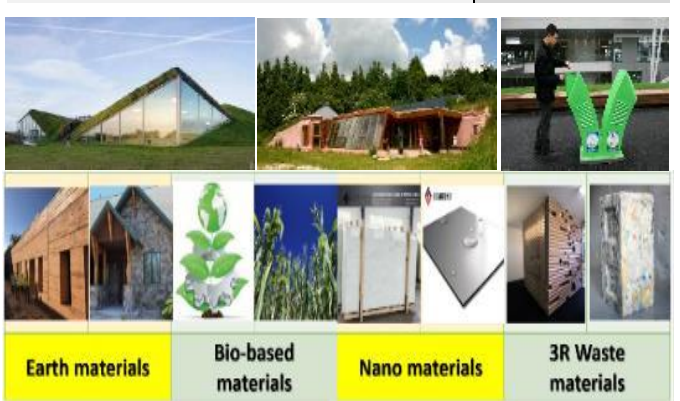

شكل (15) اعادة تنوير الموادواستخدام المخلفات البنائية الايكولوجية.

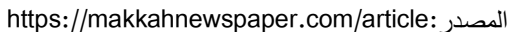


3-5 تحقيق الاحتياجات الانسانية. يذكر "Richards" أن التصميم وفق أهداف تصميمية مسؤولة الانسية

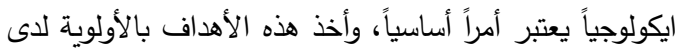

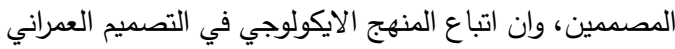

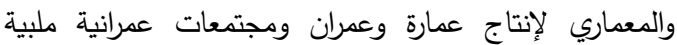
لحاجات الانسان ومؤدية الى بيئة مبنية مستدامة شكل (19)، وعندات

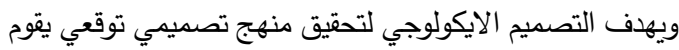

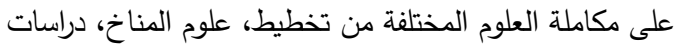

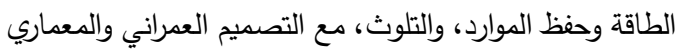

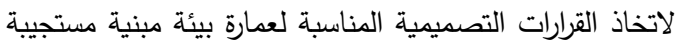

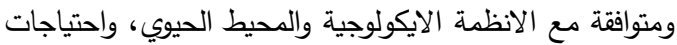

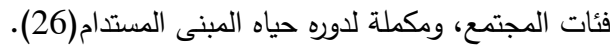

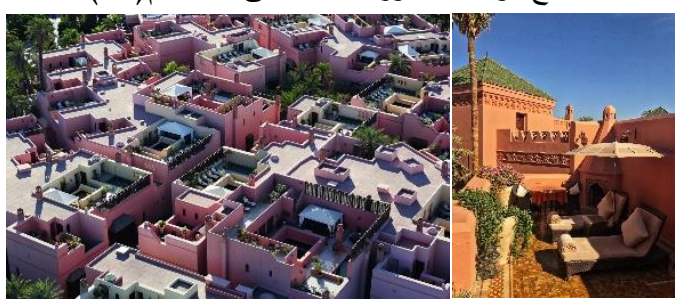

شكل (19) بيئة مبنية متو افقة مع الانظمة الإيكولوجيةو المحيط الحوي.

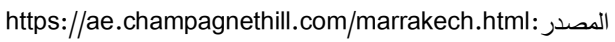

3-6 ارتفاع مؤشرات جودة الهواء. أظهرت وكالة ناسا انخفاضًا كبيرًا في ملوثات الهواء أهواء، واكد

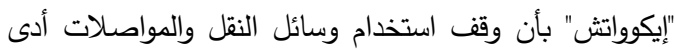
لتقليل تلوث الهواء شكل (20)، وأفادت رابطة النغات السفر الأمريكية

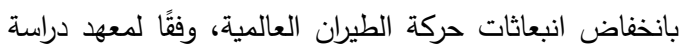

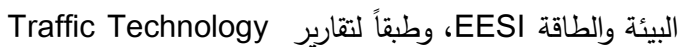
The Guardian ،Today المتحدة، والتي انخفضت بنسبة 73٪، وكثفت GEOTAB

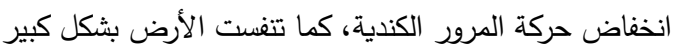
بعدما توقفت الحركة في معظم دول العالم وتحسن جودة الهواء لهاء

في 337 ددينة، مما انعكس على صحة الانسان (37).

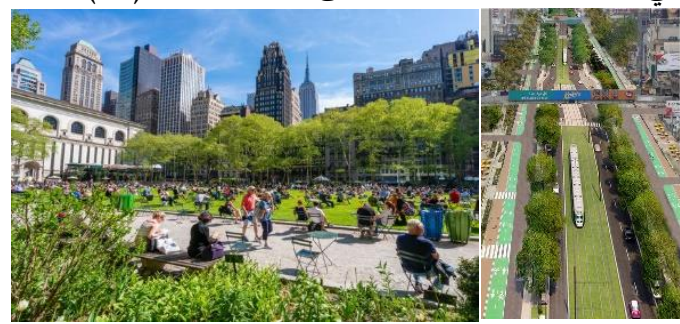

شكل (20) انخفاضًا ملوثات اليواء ونمو النباتات وزيادة كفاءة الفاغات.

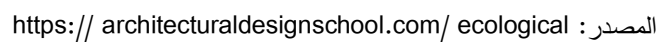

3-3 رفع مستوى الكفاءة في المباني.

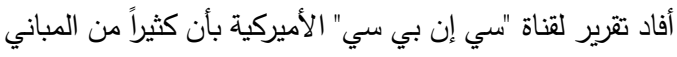

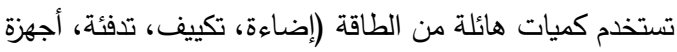

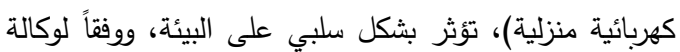

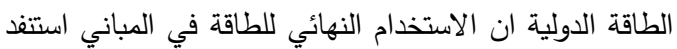

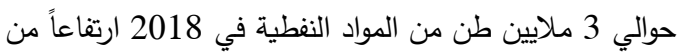

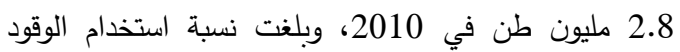

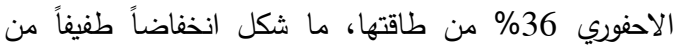

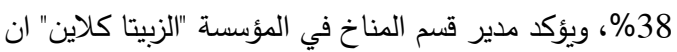

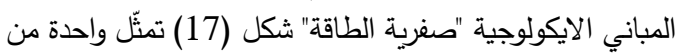
اكبر الفرص الاستثمارية طريقة تصميم البيئة المبنية لجعلها أكثر صحة ورفع مستوى الكفاءة في المباني الحديثة (24). (3) شكل (17) البيئة المبنية صفية الطاقة والاستخدام الايكولوجي للمولد.

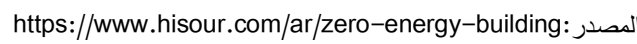

3-4 تقليل البصمة البيئية للنشاط البشري.

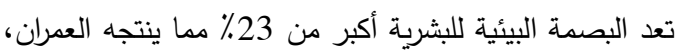

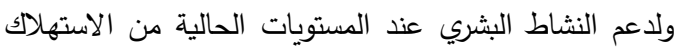

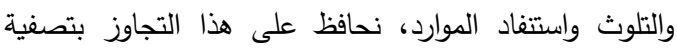

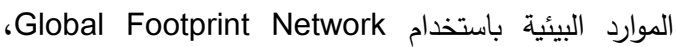

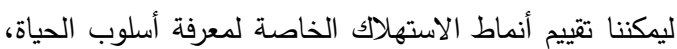

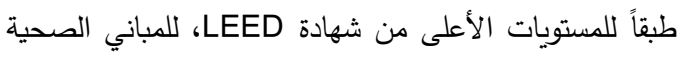

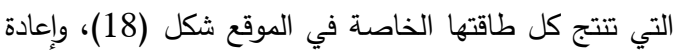

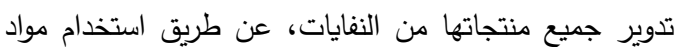
ذات محتوى معاد تدويره أو الاعتماد على الطاقة المتجددة

والحيوية، مع محاكاة الطبيعة (25).

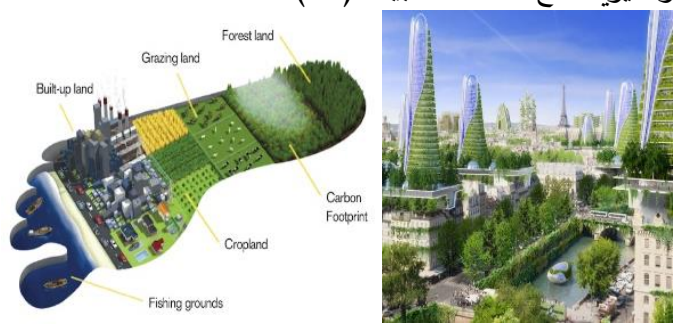

شكل (18) احت ام التقع البيولوجي ومحاكاة واستخدام الورد الطبيعة.

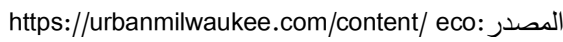


3-9-تحسين جودة البيئة الداخلية.

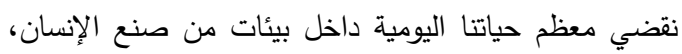

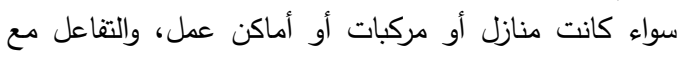

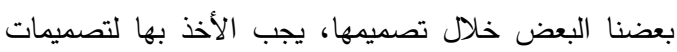

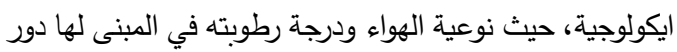

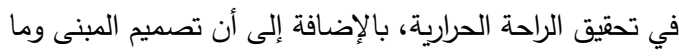

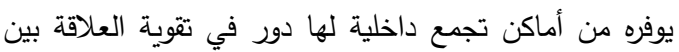

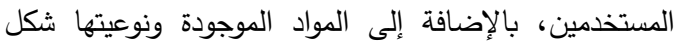

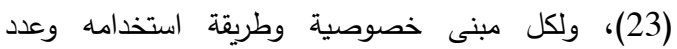
المستخدمين وأنواعهم، لذلك يلزم التعاون بين علئ وطماء البيئة والمعماريين والعمرانيين لتحقيق جودة البيئة الداخلية(28).
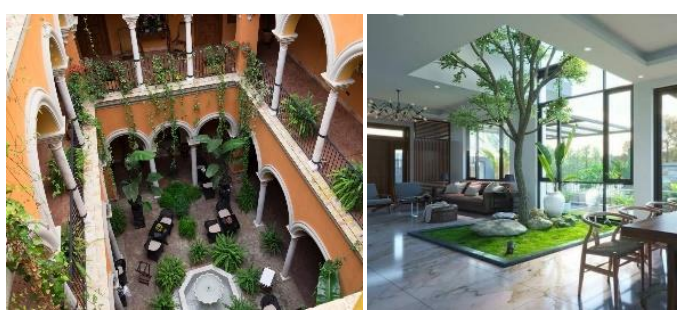

شكل (23) تحقيق جودة البيئة الداخلية وتحسين مستوى الواحة الحرلية. https://www.arch2o.com//architecture/ecohouse: المصدئ

3-10 تكامل النشاط البشري والبيئة الايكولوجية. تستخدم تقنيات إدارة واستعادة وإيجاد البيئات الطبيعية للتكامل البانئل

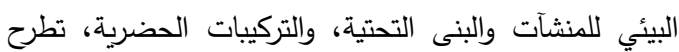

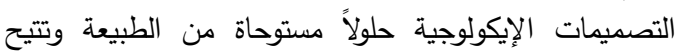

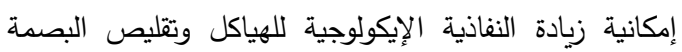

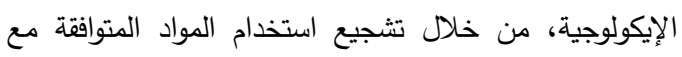
البيئة، قد تكون تقنيات إعادة استخدام الموارد مرتبطة أيضًا

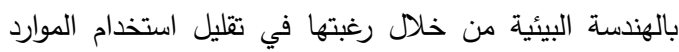

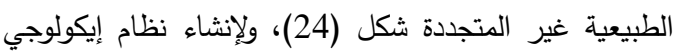

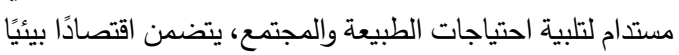
وأن يحقق الحفظ البيولوجي (31).

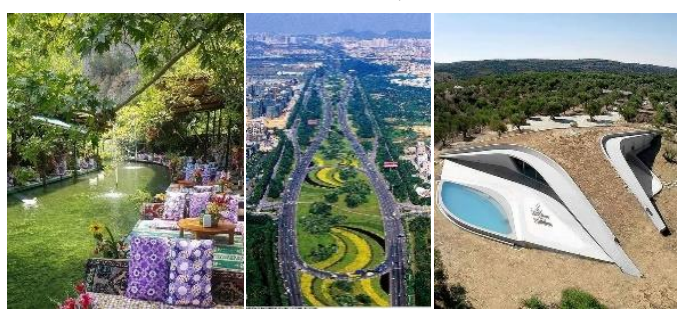

شكل (24) تكامل النظم الايكولوجية والعملة والعمران مع الأنشطة البثرية.

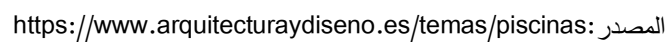

3-7 خفض انبعاثات الكربون والاحترار العالمي.

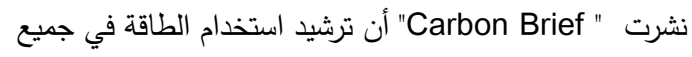

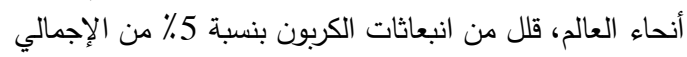

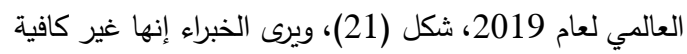

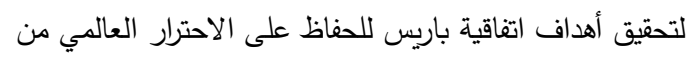

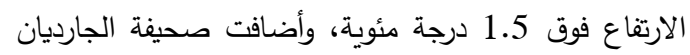

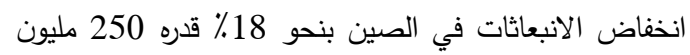

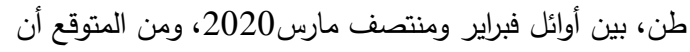

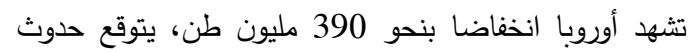

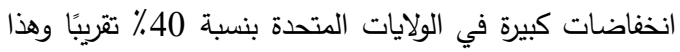
يعني أكبر انخفاض عام 2020 (27).

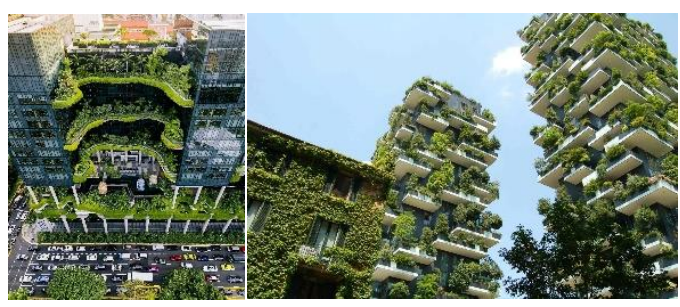

شكل (21) التصميم الايكولوجي يقلل انبعاثات الكُبون بالبيئة المبنية.

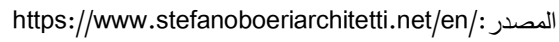

3-8 الحفاظ على النظم الايكولوجية.

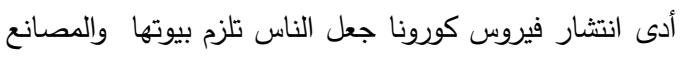

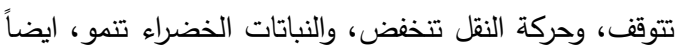

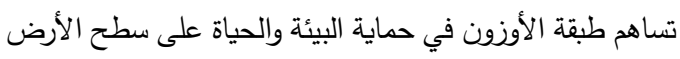

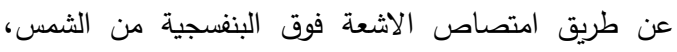

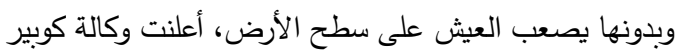

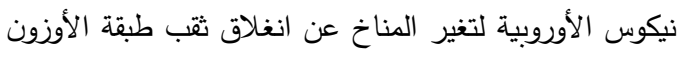

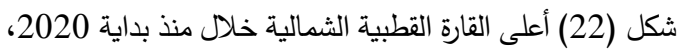

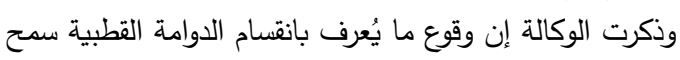

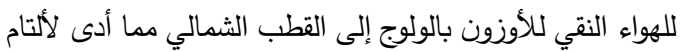
ثقب الأوزون قد فوق القارة القطبية الثمالية(34).
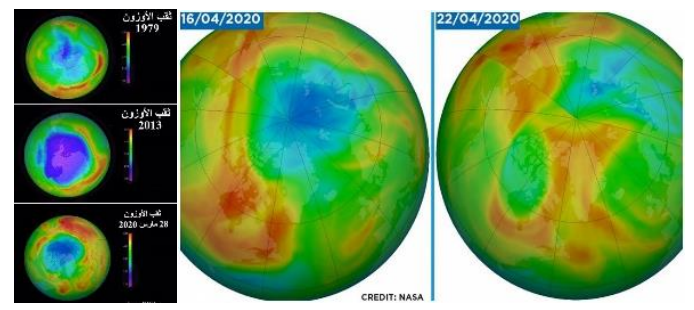

شكل (22) التقليل من ثقب الأوزون نتيجة جودة الهواء وقلة انبعاث الكربون. https://arabic.euronews.com/unprecedented-ozone: المصدر الكبون 
جدول (6) معايير اختيار عينات الدراسة التحليلية المتترحة.

\begin{tabular}{|c|c|}
\hline \multicolumn{2}{|l|}{ معايير اختيار مشروعات عينات الدراسة التحليلية } \\
\hline اعتماد تتييم الاستدامة ومنح شهادات بيئية للمشروعات. & \\
\hline تكامل العلاقات الوظيفية بالييئة المبنية والمحيط العمراني & 2 \\
\hline انعكاس البيئة الايكولوجية والعوامل المناخية بالتصميم. & 3 \\
\hline كفاءة استخدام الطاقة المتجددة وإدارة المصادر الطبيعية. & 4 \\
\hline استخدام التكنولوجيا المتوافقة مع البيئة وأسلوب الإنشاء. & 5 \\
\hline توفير احتياجات المستخدمين ومراعاة المبادئ الخضراء. & 6 \\
\hline مدى قدرة المباني لمواجهة المتغيرات المستقبلية. & \\
\hline
\end{tabular}

جدول (7) أسماء ومواقع مشروعات عينات الدراسة التحليلية.

أسماء مشروعات عينات الاراسة التحليلية

\begin{tabular}{|c|c|c|}
\hline الموقع - م المع & اسم المشروع & s \\
\hline United States & Center for Sustainable Landscapes & 1 \\
\hline China & Shanghai Natural History Museum & 2 \\
\hline Singapore & Kampung Admiralty & 3 \\
\hline Netherlands & The Edge Building & 4 \\
\hline Italy & Vertical Forest & 5 \\
\hline
\end{tabular}

4-2 عناصر وأدوات التقييم للمنهجية المقترحة. تم طرح مدخل منهجي وفق أسس ومعايير علمية تساهم في

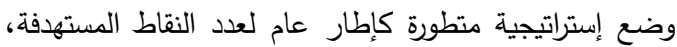
وصياغتها في صورة جدول لتتيييم المنهجية المقترحة يتم تقيييم

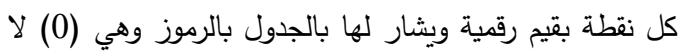

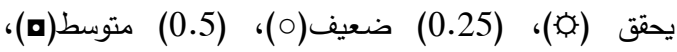

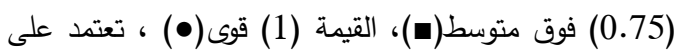

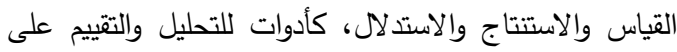
المستوى العمراني والمعماري، وذلك استناداً للتوجيهات النظرية والتئية

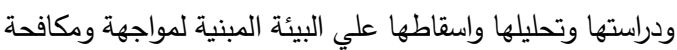

التحديات والقضايا والمتغيرات، كما بالجدول(8) التالي: -

جدول (8) عناصر ونقاط تقييم المنهجية المقترحة.

\begin{tabular}{|c|c|c|c|c|c|c|}
\hline مجموع & الاهداف & المبادئ & المقومات & المعايير & \multicolumn{2}{|c|}{ أنظمة الالاستالهتبارات } \\
\hline 35 & 12 & 8 & 7 & 8 & الجوانب & 5 \\
\hline 35 & 12 & 8 & 7 & 8 & البيئيسة & 1 \\
\hline 35 & 12 & 8 & 7 & 8 & الاجتماعية & 2 \\
\hline 35 & 12 & 8 & 7 & 8 & الصحية & 3 \\
\hline 35 & 12 & 8 & 7 & 8 & الاقتصادية & 4 \\
\hline 35 & 12 & 8 & 7 & 8 & المــوارد & 5 \\
\hline 175 & 60 & 40 & 35 & 40 & \multicolumn{2}{|c|}{ مجموع النقاط } \\
\hline
\end{tabular}

3-12معايير قياس الجودة الإيكولوجية المستدامة.

مع تقدم العلم في القرن الحادي والعشرين سيكون للتكنولوجيا

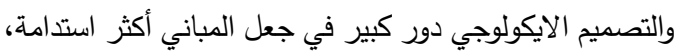

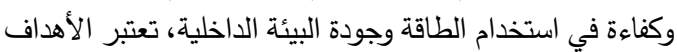

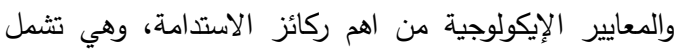

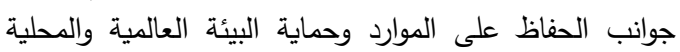

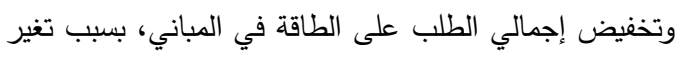

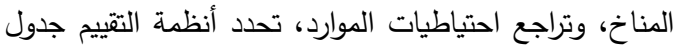

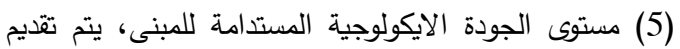
الاليل على ذلك من خلال شهادة اعتماد البناء(27). جدول (5) الأنظمة المعتمدة لتقييم التصميم الايكولوجي المستدام.

\begin{tabular}{|c|c|c|}
\hline الاختصار & وصف نظام التقييم & 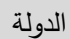 \\
\hline (LEED) & القيادة في الطاقة والتصميم البيئي & USA \\
\hline (USGBC) & المجلس الآمريكي للبناء الأخضر & USA \\
\hline$($ IGCC) & كود البناء الآخضر الدولي & USA \\
\hline (IWBI) & معهز ويل الدولي للبناء & USA \\
\hline$(\mathrm{LBCC})$ & تصديق التحدي في بناء المعيشة & USA \\
\hline (BREEAM) & الآتقييم البيئي لمؤسسة أبحاث البناء & UK \\
\hline (DGNB) & المجلس الألماني للبناء المستدام & GER \\
\hline (SB TOOL) & الأداء البيئي واستدامة المباني & CAN \\
\hline (HK- BEAM) & طرق التقييم البيئي للمباني & JAP \\
\hline (PBRS) & نظام التُقييم بدرجات اللؤلؤ للمباني & UAE \\
\hline (GSAS) & نظام تقييم الاستدامة الثامل & QAT \\
\hline (SGBC) & المجلس السعودي للمباني الخضراء & KSA \\
\hline (GPRS) & نظام التقييم الهرم الأخضر & EGP \\
\hline
\end{tabular}

4 الاراسة التحليلية- تقييم اعتبارات التصميم الايكولوجي.

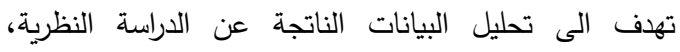

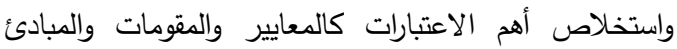

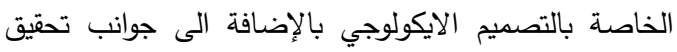

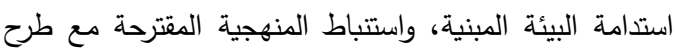

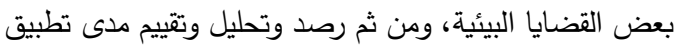

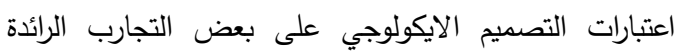

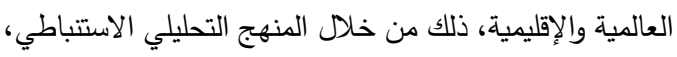

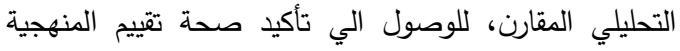
المقترحة مع مطابقتها لإثبات الفرضية وتحقيق هدف البحت البحث. 4-1معايير اختيار عينات الدراسة التحليلية.

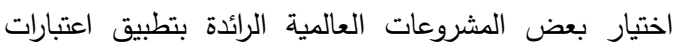

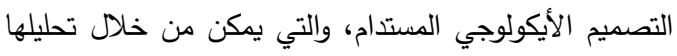
وتقييم مدى تطبيقها لتلك الاعتبارات جدول (6)، ومن ثم اختبار

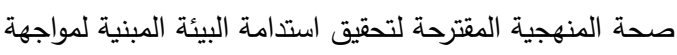
المتغيرات المستقبلية، ذلك طبقاً لجدول (7) كما يلي: - 


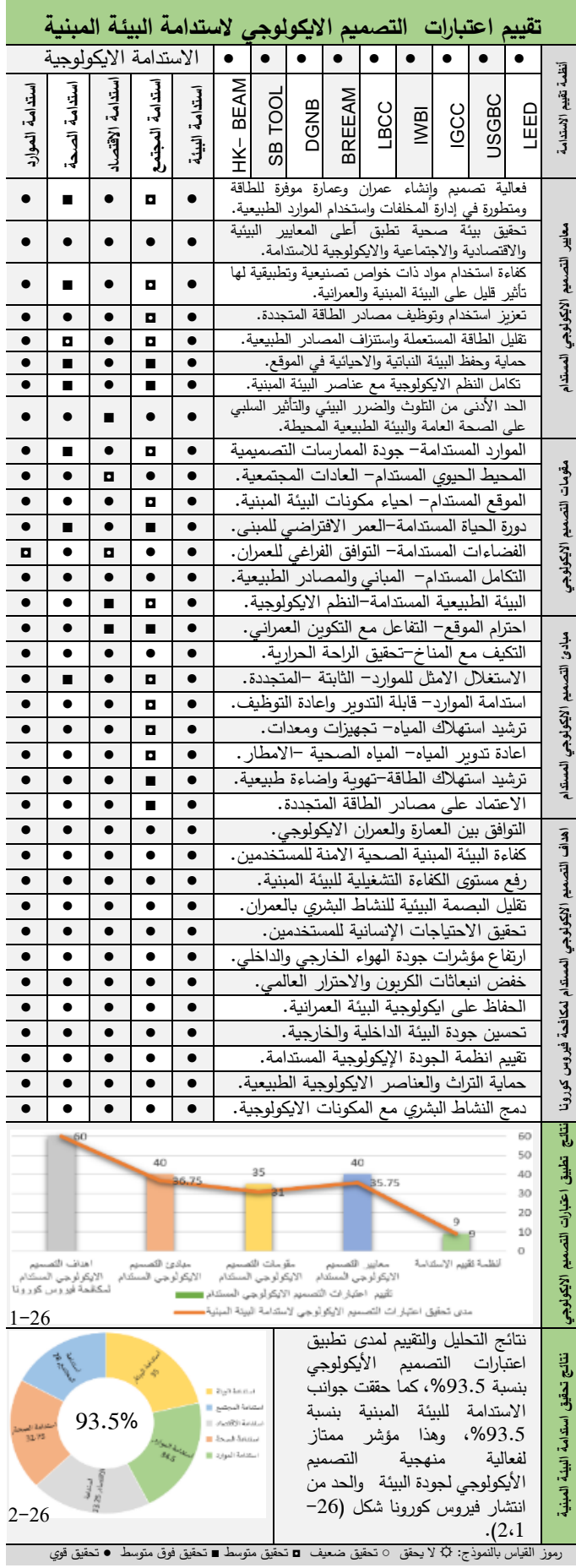

شكل (26-1،2) مؤشرات تقييم الاعتبارات الايكولوجية والاستدامة.
تطبيق اعتبارات التصميم الايكولوجي لاستدامة البيئة المبنية Center for Sustainable Landscapes

The Design Alliance Architects PITTSBURGH, UNITED STATES

1 1

مركز المناظر الطبيعية المستدامة (CSL) هو مبنى للتعليم والبحث

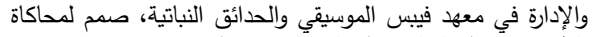

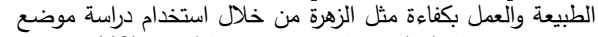

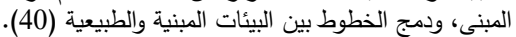

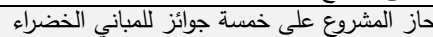

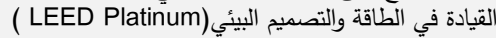

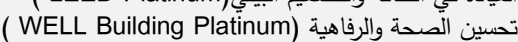
أربع نجوم للمواقع المستدامة (Four Stars Sustainable Sites) تحدي حيونة المباني) (Living Challenge SM) الجائزة البلآتينية للمباني الجيدة (SITES)

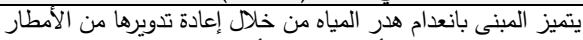

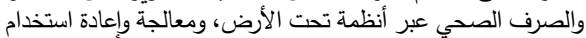
جميع المياه الرمأدية ومياه العواصف التئ التي يتم التقاطهاً في الموقع،

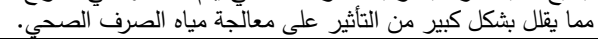

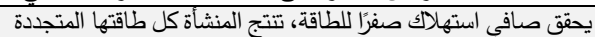

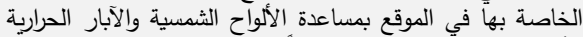

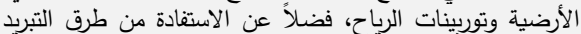

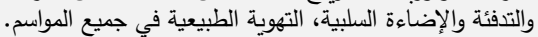

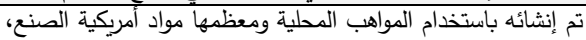

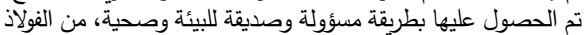

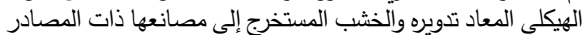

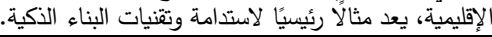

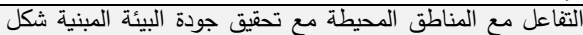

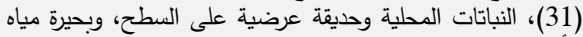
الأمطار، ونظام تقطير المياه بالطاقة الثمسية، وخمس حدائية وائق

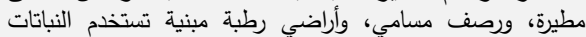

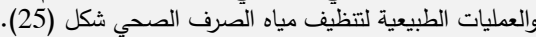

يستخدم نظام التدفئة والتهوية وتكييف الهياه الهواء الأرضي (HVAC)

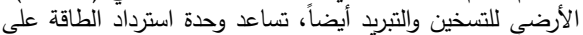

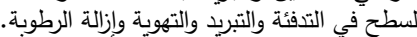

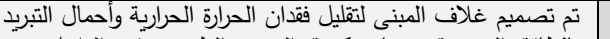

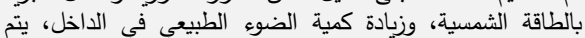

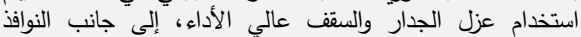

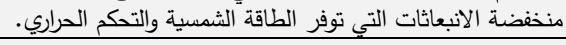

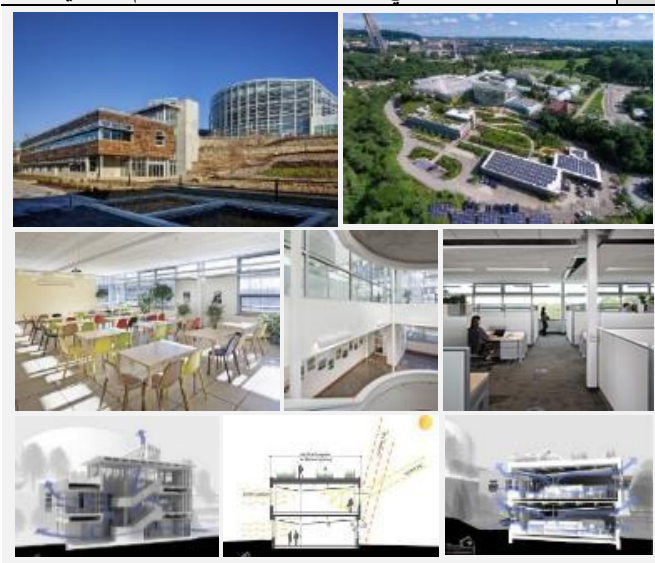

شكل (25) التكامل مع المحيط العمراني وجودة البيئة الداخلية. 
جدول (12) تقييم تحقيق الاعتبارات الايكولوجية بالمشروع الثاني

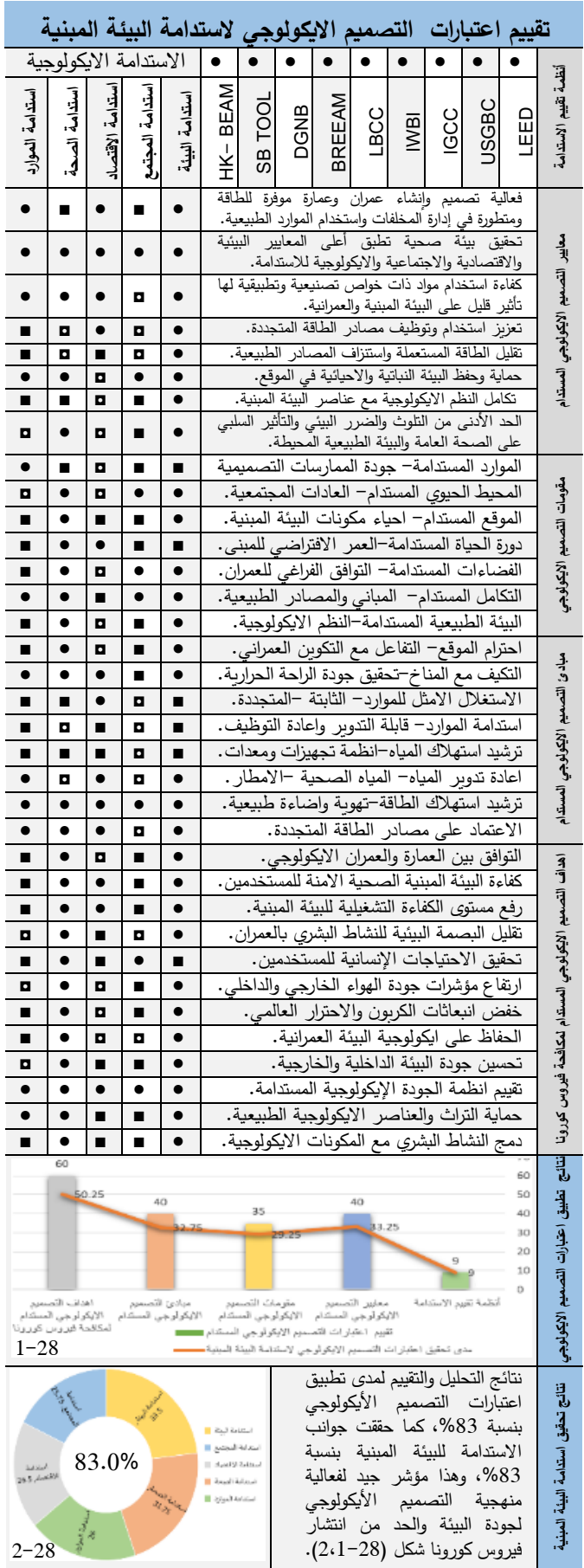

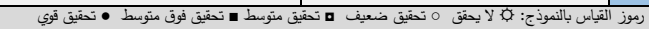

شكل (28-1،2) مؤشرات تقييم الاعتبارات الايكولوجية والاستدامة.
جدول (11) تحليل تطبيق الاعتبارات الايكولوجية بالمشروع

تطبيق اعتبارات التصميم الايكولوجي لاستدامة البيئة المبنية Shanghai Natural History Museum

\begin{tabular}{|c|c|}
\hline Perkins +Will & المعماري \\
\hline Shanghai, China & الموقع \\
\hline
\end{tabular}

مبنى مستوحى من علاقة الإنسان بالطبيعة ودمجها مع الهندسة

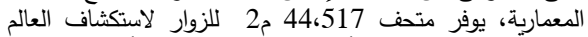
الطبيعي من خلال عرض أكثر من

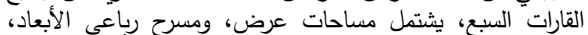
وحديقة معارض خارجية، وأتريوم بطول 30 مترًاً (33).

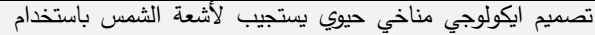

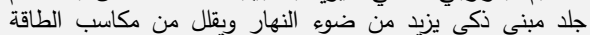

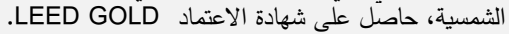

يتضمن سقف أخضر يتكامل مع البيئة الطبيعية، ويجمع بين التصاد التصميم

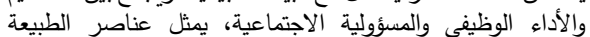

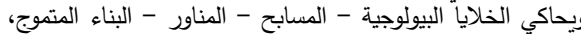

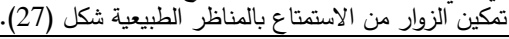

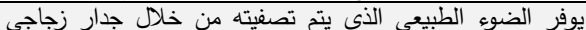

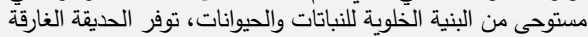

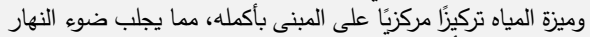

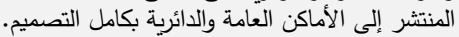

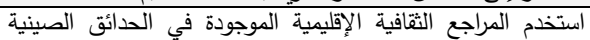

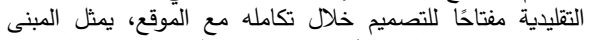

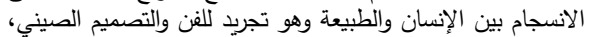

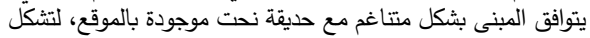

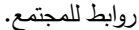

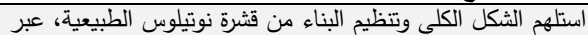

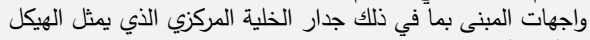

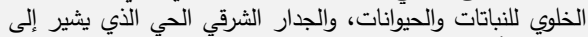

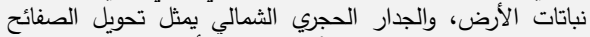

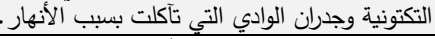

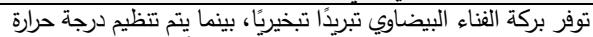

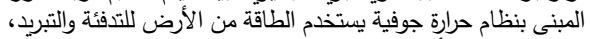

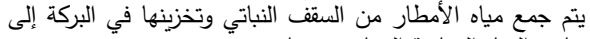
جانب المياه الرمادية المعاد تدويرها.

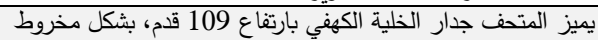
بيضاوي من ثلاث طبقات هندسية عضوية، تؤكد الطبقة الرئيسية

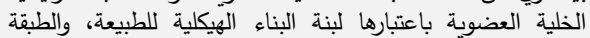

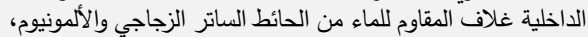

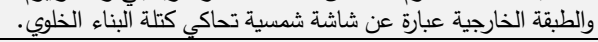

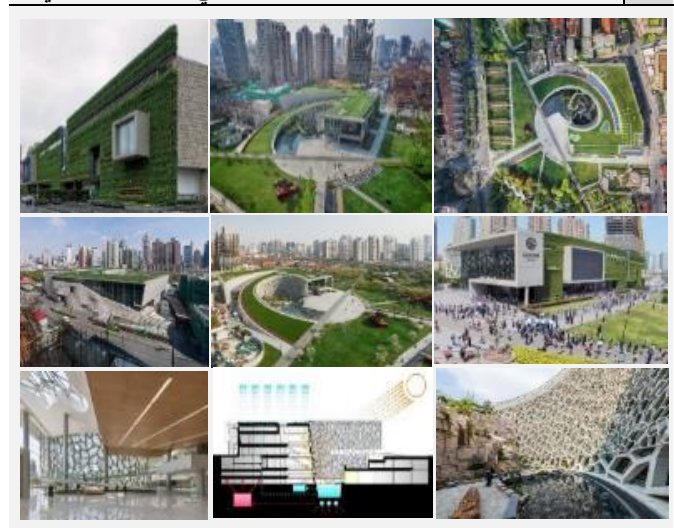

شكل (27) التكامل الايكولوجي مع الموقع وتحقيق جودة البيئة. 
جدول (14) تقييم تحقيق الاعتبارات الايكولوجية بالمشروع الثالث

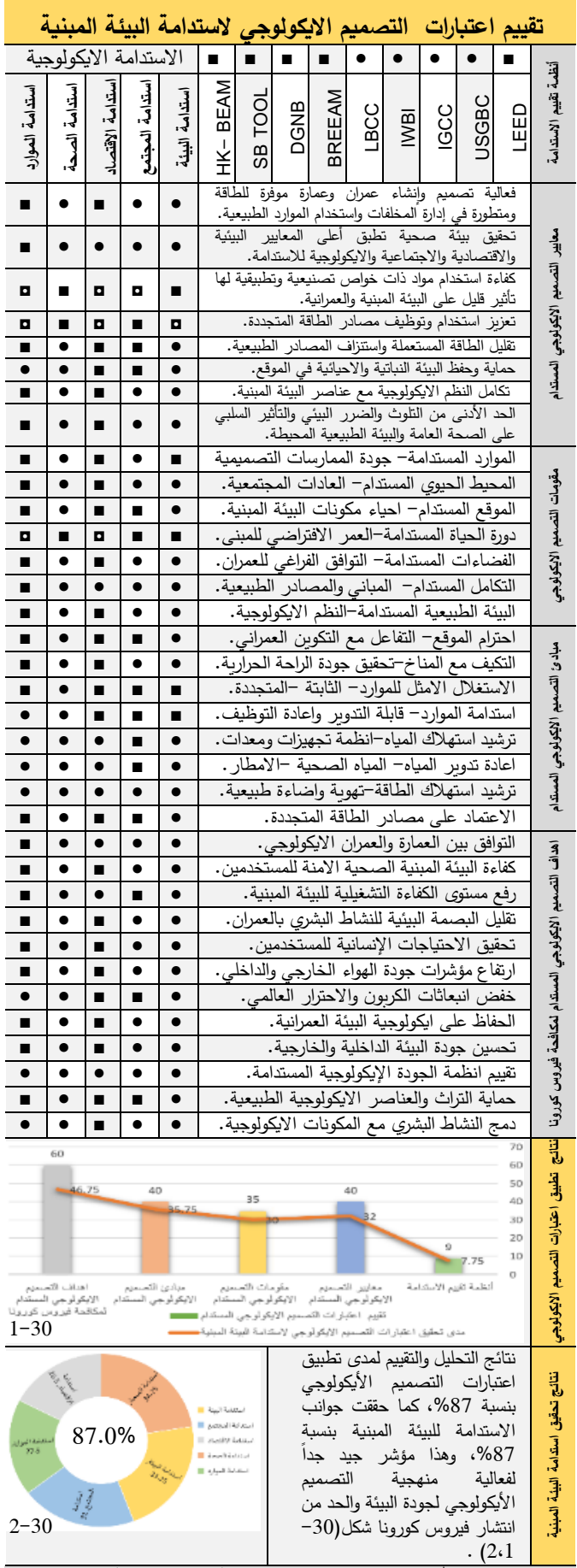

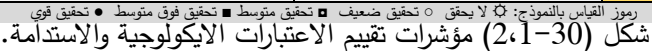

جدول (13) تحليل تطبيق الاعتبارات الايكولوجية بالمشروع الثاني

تطبيق اعتبارات التصميم الايكولوجي لاستدامة البيئة المبنية Kampung Admiralty

Ramboll Studio Draisaitl

3 3

مركز مجتمعي متكامل للمسنين في حي الضواحي عالي الكثافة،

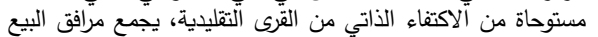

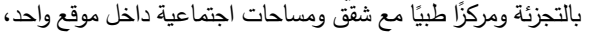

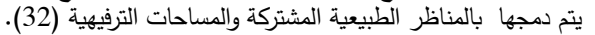

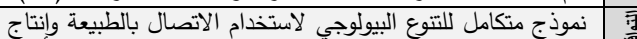

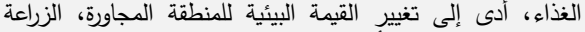

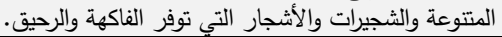

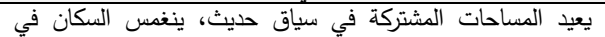
الطبيعة طوال اليوم، يحسن الصحة العقلية ويشجيع النشاط البندي،

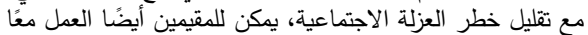

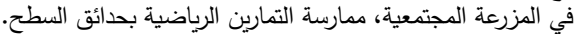

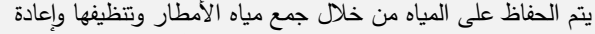

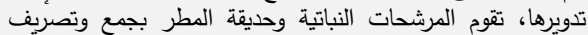

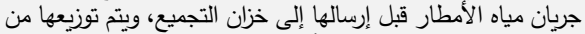

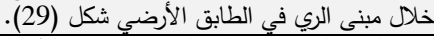

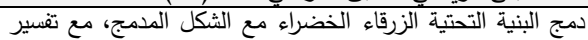

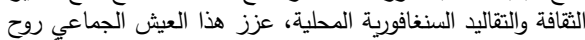

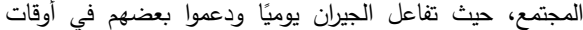

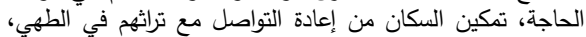
ونقل المعرفة بالمنتجات المحلية والأطباق التقليدية إلى الجيل التالئي. حولت الجزيرة مناظرها الحضرية في غضون المنات الفيل واحد من خلال

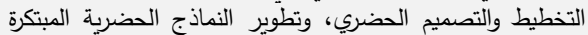

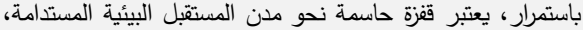

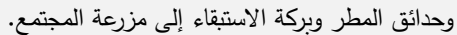

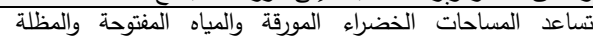

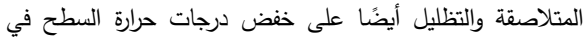
الموقع، يحقق مساحات خارجية ممتعة في الحرارة الاستوائية.

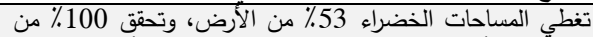
الاستبدال الأخضر ، يدير هذا الموارد الطبيعية للموقع أكثر من كونها لأكنا

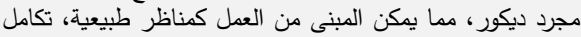

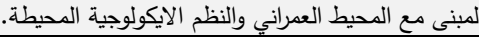

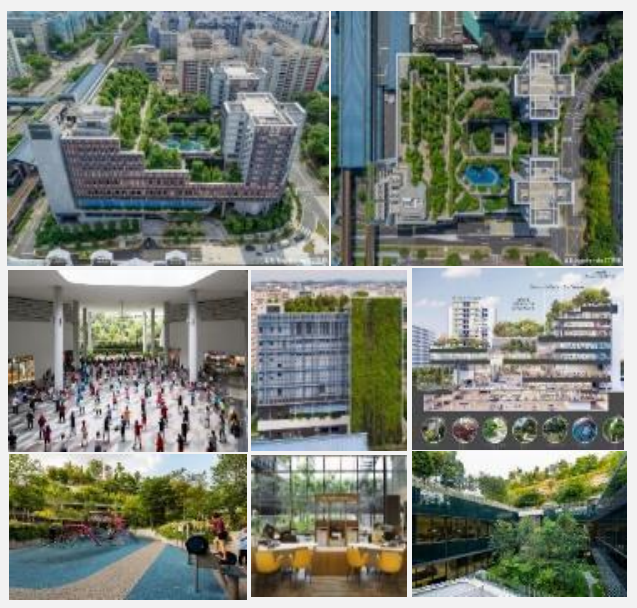

شكل (29) التوافق البيئي مع الموقع واستدامة البيئة المبنية. 
جدول (16) تقييم تحقيق الاعتبارات الايكولوجية بالمشروع الرابع

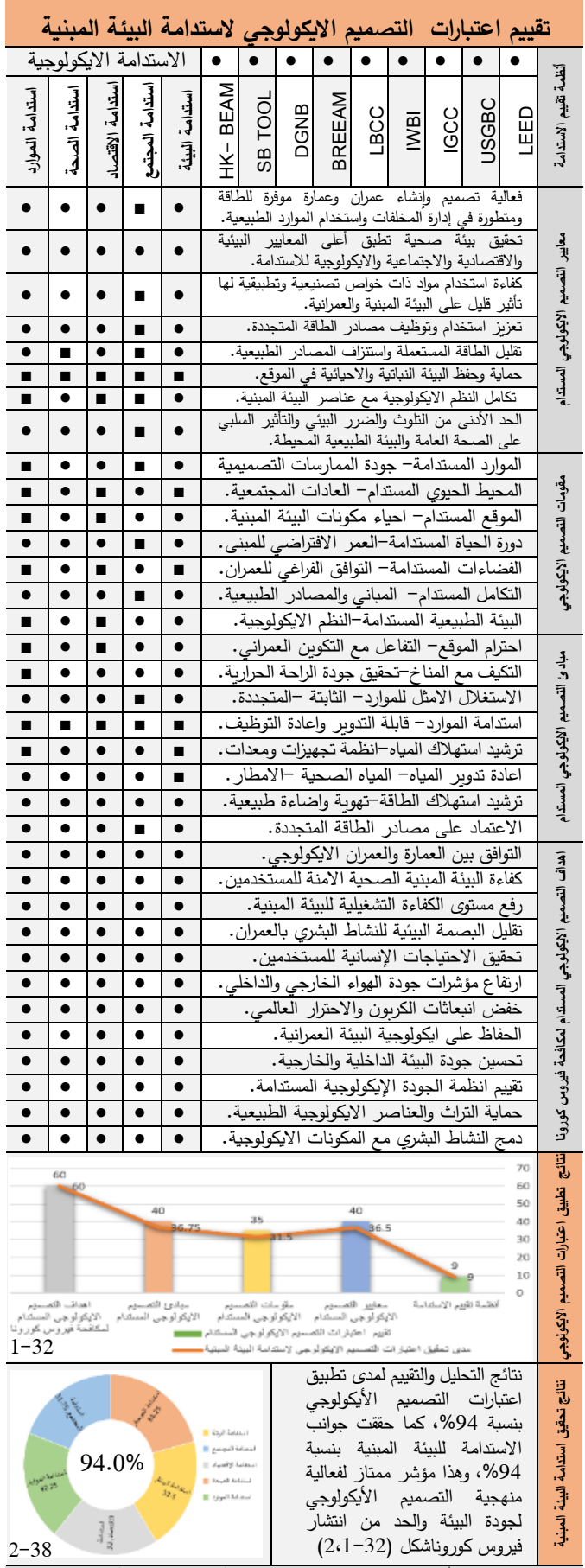

$2-38$

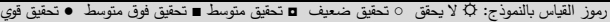

جدول (15) تحليل تطبيق الاعتبارات الايكولوجية بالمشروع الرابع

تطبيق اعتبارات التصميم الايكولوجي لاستدامة البيئة المبنية The Edge Building

PLP Arch. \& Fokkema \& Partners

4

Amsterdam- Netherlands

هو مبنى إداري تبلغ مساحته 40000 م2 يحتوي على 15 طابق،

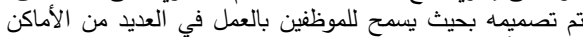

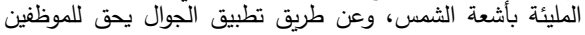

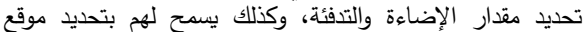

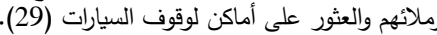

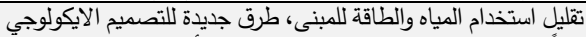

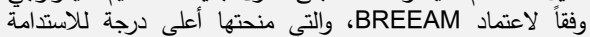

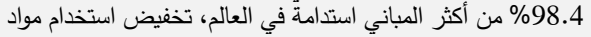

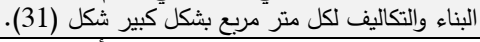

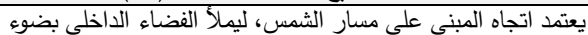

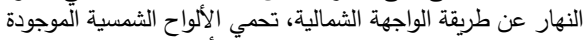

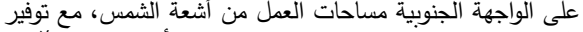

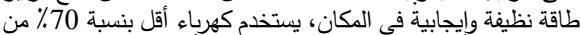
المباني المكتبية المماثلة، انخفاض تكالية لواليف الطاقة والصيانة.

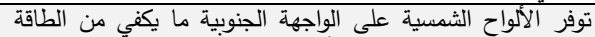
لتشغيل جميع الهواتف الذكية وأجهزة الحاسوب والكوبة والسيارات الكهربائية،

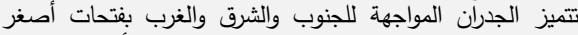

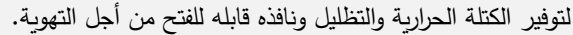

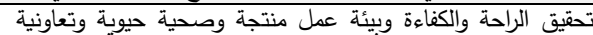

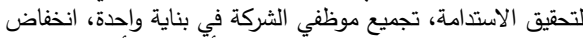

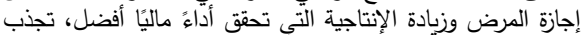

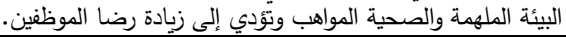

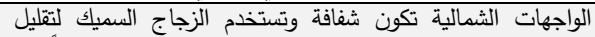

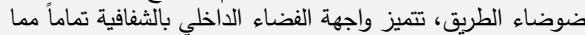

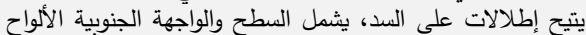
الكهروضوئية، يتم قياس الإشغال باستخدام التكنولوجيا الذئل الذيكية.

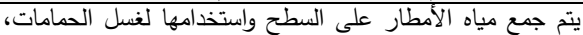

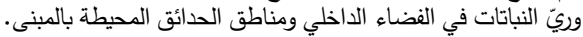

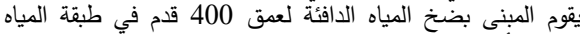

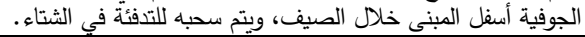

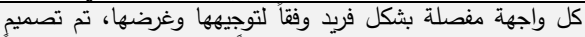

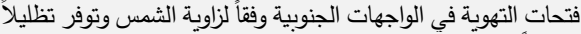

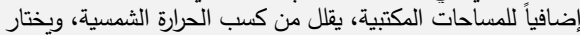

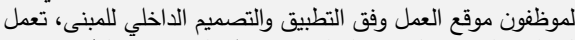
المساحة الخضراء كممر إيكولوجي يفصل ولئل المبنى عن الطريق.

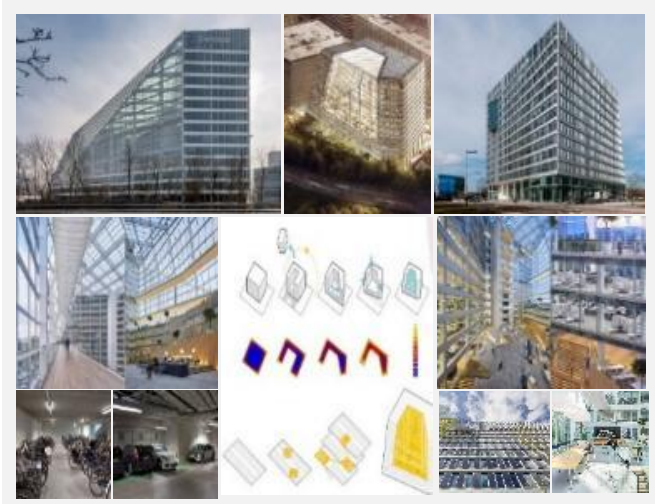

شكل (31) التكامل مع الموقع وتحقيق جودة البيئة المبنية. 
جدول (18) تقييم الاعتبارات الايكولوجية بالمشروع الخامس.

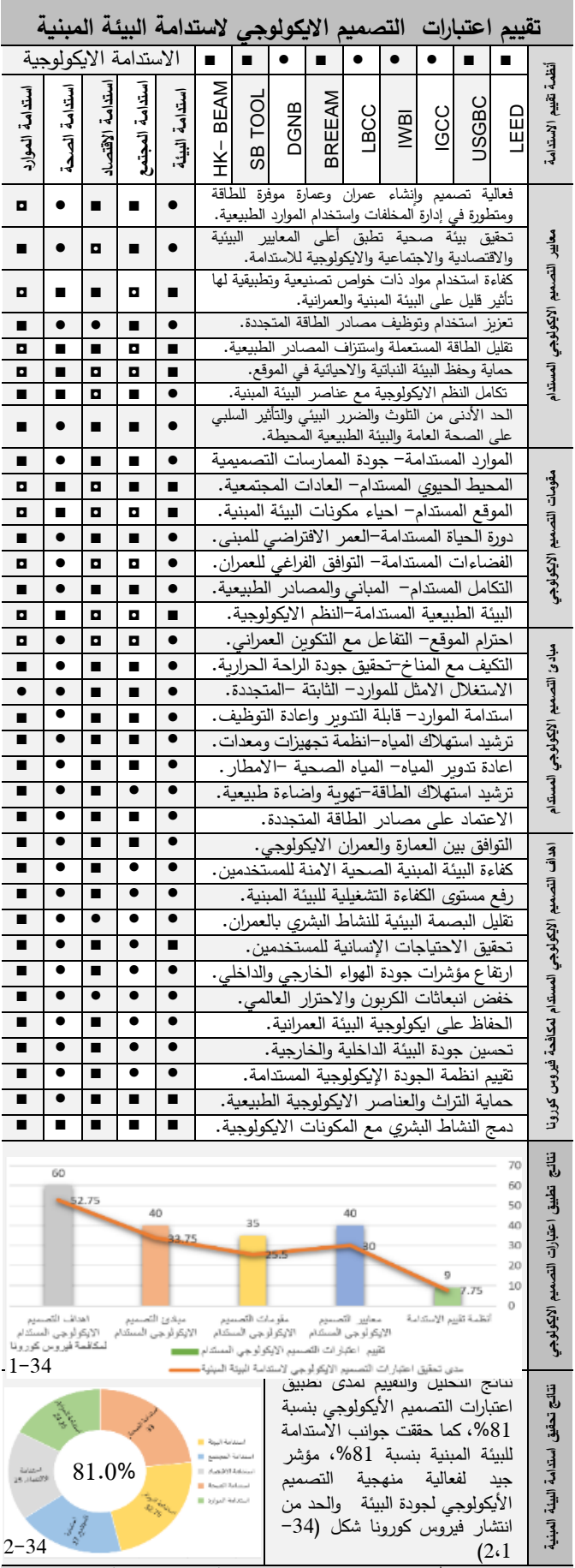

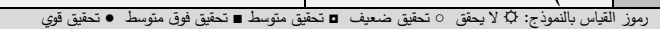

شكل (34-2،2) مؤشرات تثييم الاعتبارات الايكولوجية والاستدامة.
جدول (17) نطبيق الاعتبارات الايكولوجية بالمشروع الخامس.

\begin{tabular}{|c|c|c|}
\hline يم الايكولوجي لاستدامة البيئة المبنية & ل اعتبارات ات اعبات & \\
\hline Vertical Forest & المشروع & رقم \\
\hline Stefano Boeri Architect & 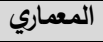 & \\
\hline ITALY-MILAN & الموقع - الم & \\
\hline
\end{tabular}

| أطلقت شركة Boeri Studio الغابات العمودية وسط مدينة ميلان،

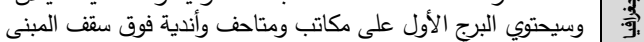

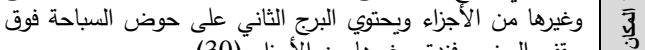

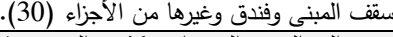

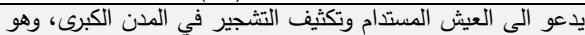

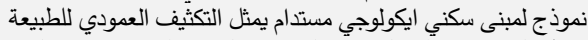

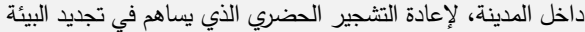
والتتوع البيولوجي في المناطق الحضرية من دون الآثار "المترتبة على لئي

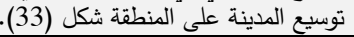

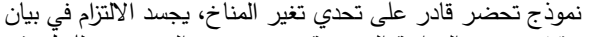

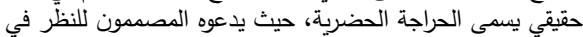
المشاكل المقلقة المتعلقة بالاحترار العالمي والتلوث على الكئل الكوكب،

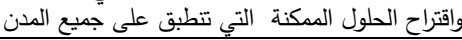

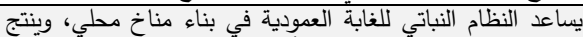

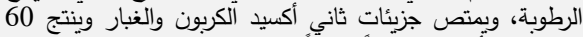

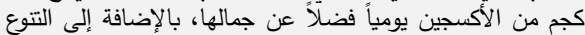
البيولوجي للنباتات، تستفيد الحيوانات أيضًا من الغابة العمودية، وجدت أنواع مختلفة من الحشرات والطيور موطنها الطبيعي تلقائيًا.

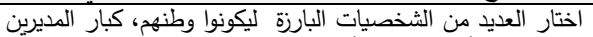

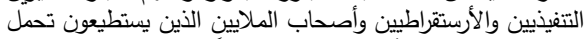

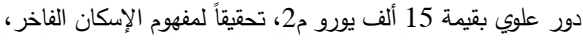

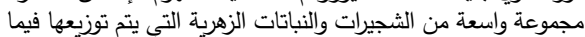

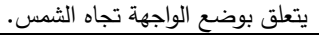

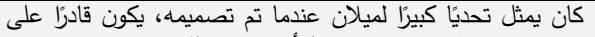

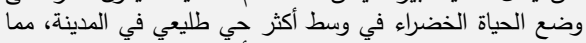
يخلق واحة في وسط المدينة الرمادية، أصبحت نمونجئا سيتم نسخه

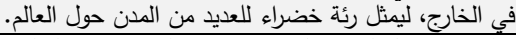

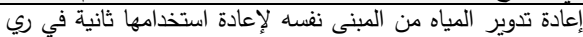

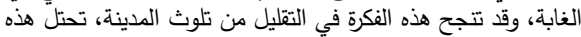

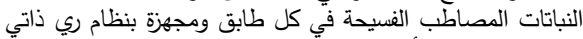

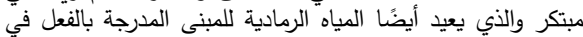

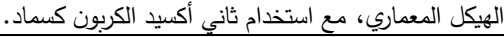

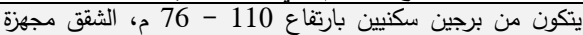

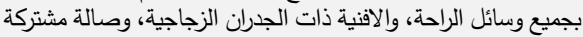

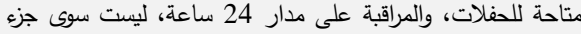
من الفخامة التي يمكن اللسكان المحظوظين الاستمتاع بها.

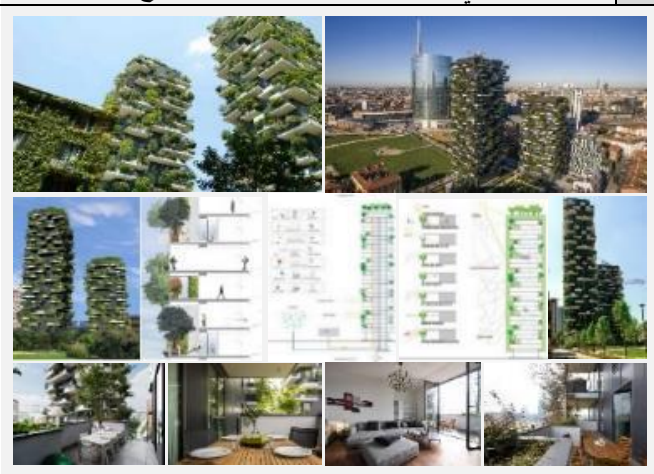

شكل (33) المبادئ الخضراء تحقق التكامل الايكولوجي للمبني. 
3-4 نتائج الاراسة التحليلية.

3-3-4 علي مستوى تحقيق جوانب استدامة البيئة المبنية.

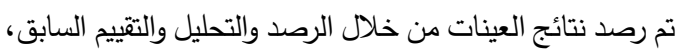

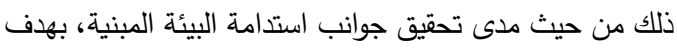

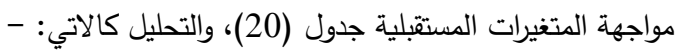

جدول (20) نتائج تحقيق جوانب استدامة البيئة المبنية.

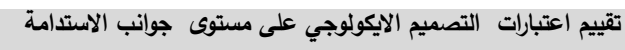

\begin{tabular}{|c|c|c|c|c|c|c|}
\hline مجموع & الموارد & الصحة & الاقتصاد & المجتمع & البيئة & \multirow{2}{*}{ العينة } \\
\hline 175 & 35 & 35 & 35 & 35 & 35 & \\
\hline 163.5 & 34.5 & 33.3 & 32.8 & 28 & 35 & 1 \\
\hline 145.5 & 28 & 31.8 & 26.5 & 25.8 & 33.5 & 2 \\
\hline 152.5 & 27.5 & 34.3 & 26.5 & 31 & 33.3 & 3 \\
\hline 164.8 & 32.3 & 34.3 & 33 & 31.8 & 33.5 & 4 \\
\hline 142 & 24.3 & 33 & 25 & 27 & 32.8 & 5 \\
\hline 768.3 & 146.5 & 166.5 & 143.8 & 143.5 & 168 & 800 \\
\hline
\end{tabular}

4-4-4مقارنة مدى تحقيق العينات لجوانب الاستدامة.

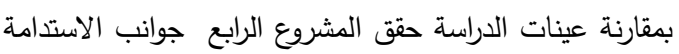

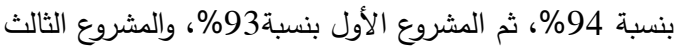

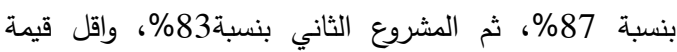
المشروع الخامس بنسبة 81\%، كما هو موضح بالثكل (37).

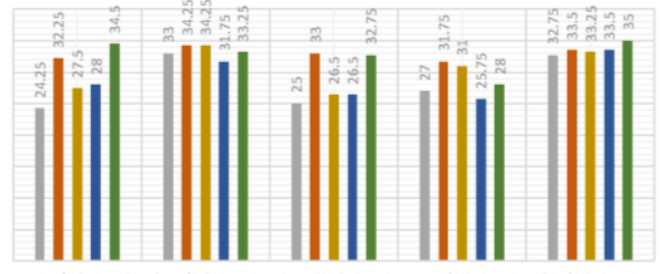

- Center for Sustainable Landscapes @ Shanghai Natural History Museum

- Kampung Admiralty - The Edge Building

= Vertical Forest

شكل (37) مدى تحقيق العينات لجوانب الاستدامة الايكولوجية.

4-4-4-5مقارنة تحقيق جوانب الاستدامة.

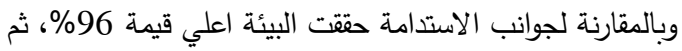

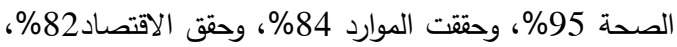

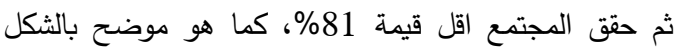

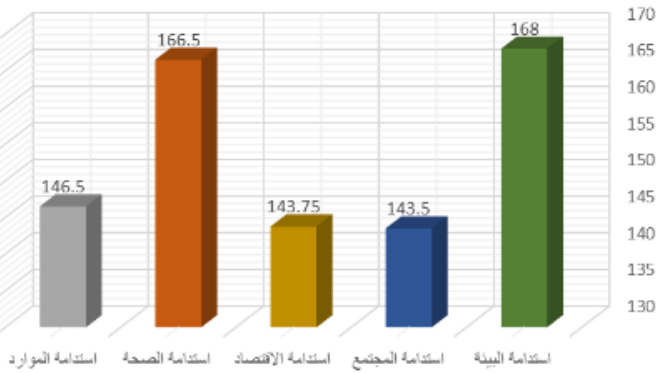

شكل (38) مدى تحقيق جوانب الاستدامة بالبيئة المبنية.

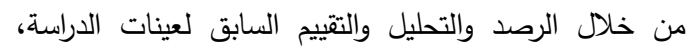

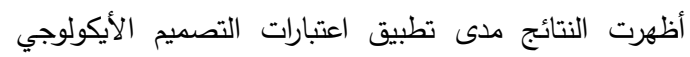

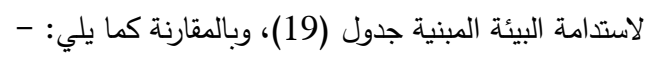
جدول (19) نتائج تقييم اعتبارات التصميم الأيكولوجي.

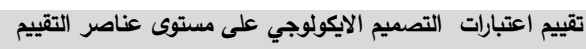

\begin{tabular}{|c|c|c|c|c|c|c|}
\hline مجموع & الاهداف & المبادئ & المقومات & المعايير & الأنظمة & \multirow{2}{*}{ العينة } \\
\hline 184 & 60 & 40 & 35 & 40 & 9 & \\
\hline 172.5 & 60 & 36.8 & 31 & 35.8 & 9 & 1 \\
\hline 154.5 & 50.3 & 32.8 & 29.3 & 33.3 & 9 & 2 \\
\hline 152.3 & 46.8 & 35.8 & 30 & 32 & 7.8 & 3 \\
\hline 173.8 & 60 & 36.8 & 31.5 & 36.5 & 9 & 4 \\
\hline 149.8 & 60 & 36.8 & 31 & 35.8 & 9 & 5 \\
\hline 802.8 & 269.8 & 175.8 & 147.8 & 167.5 & 42.5 & مجموع \\
\hline
\end{tabular}

4-3-4 علي مستوى تطبيق اعتبارات التصميم الايكولوجي

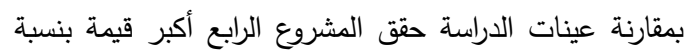

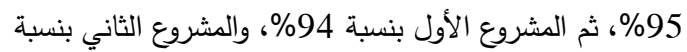

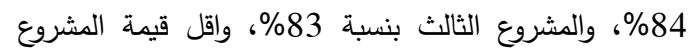
الخامس بنسبة 81\%، كما هو موضح بالثكل (35).

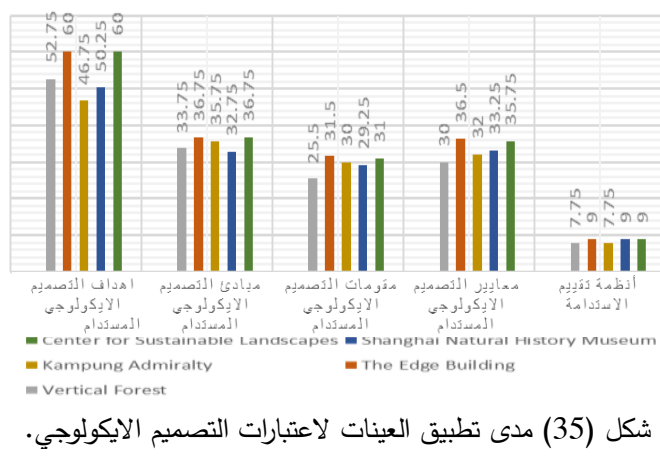
4-3-2-2مقارنة مدى تطبيق عناصر التقييم.

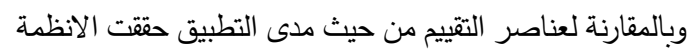

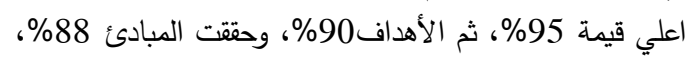

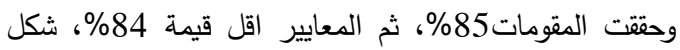

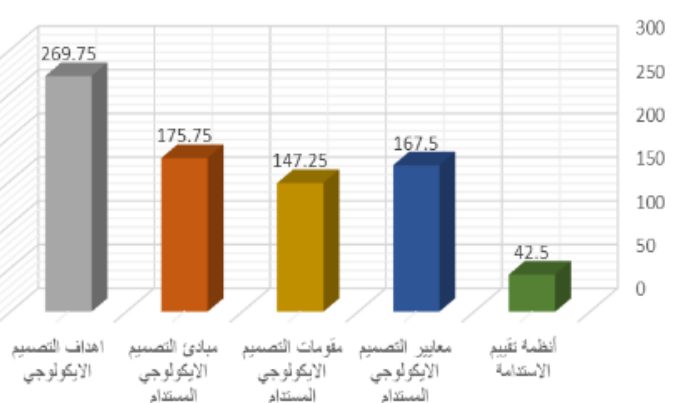

شكل (36) مدى تحقيق عناصر تقييم اعتبارات الأيكولوجية. 
4-5طرح منهجية تطبيق اعتبارات التصميم الايكولوجي لاستدامة البيئة المبنية. المنهجية المقترحة ليست منفصلة عن أنظمة ومنهجيات التصميم

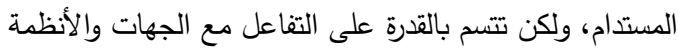

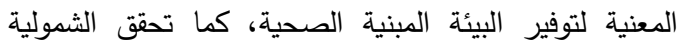
والمرونة بما يسمح بتطبيقها بجميع المشروعات ومختلف أنواعها

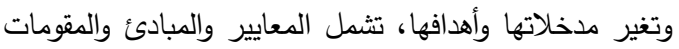

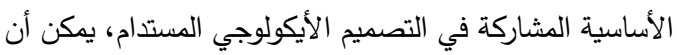

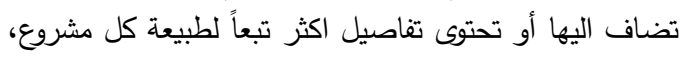

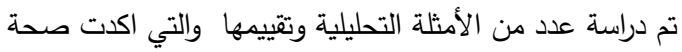

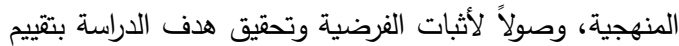
تطبيق اعتبارات التصميم الأيكولوجي لتحقيق استدامة البيئة المبنية لمواجهة المتغيرات المستقبلية شكل (41).

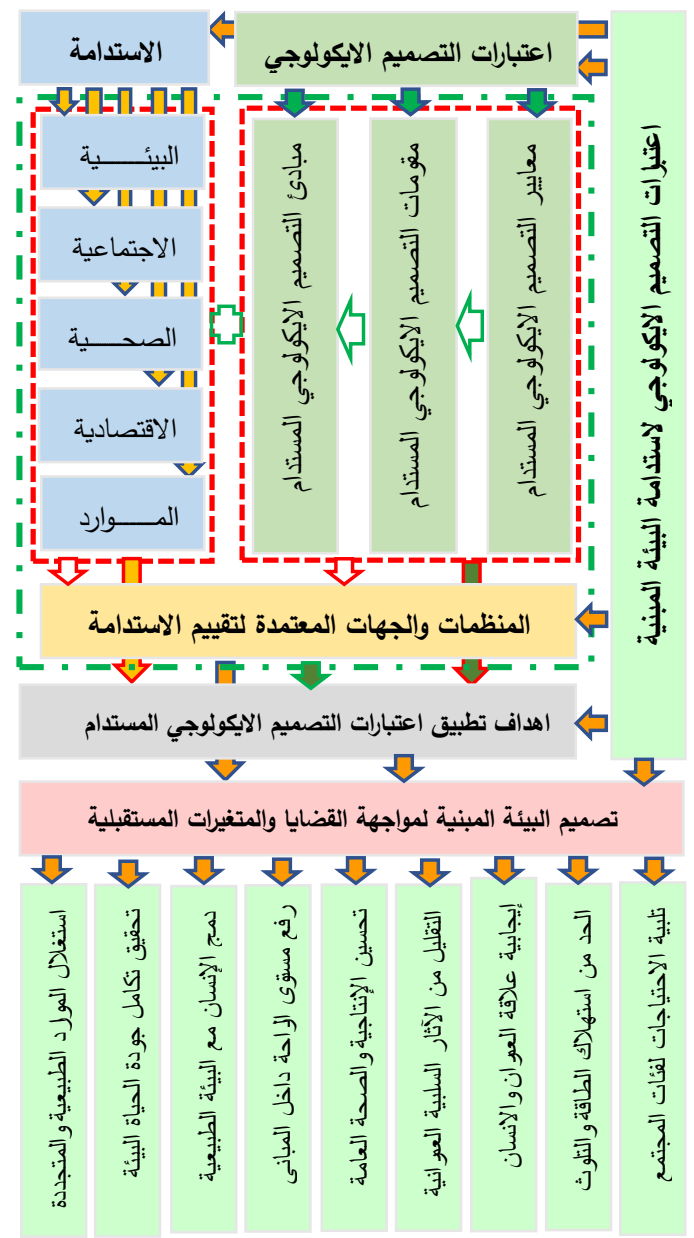

شكا ، (41) منصحة تطسة ، اعتارات التصمد الأكهلهح. المستداد.
الاكولو-4-4مقارنة مدى تقييم تطبيق اعتبارات التصميم الايكولوجي وتحقيق استدامة البيئة المبنية.

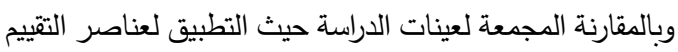
وتحقيق اعتبارات التصديم الايكولوجي المستدام بالبيئة المبنية، حققت اهداف مواجهة المتغيرات المستقبلية 90\% شكل (39).

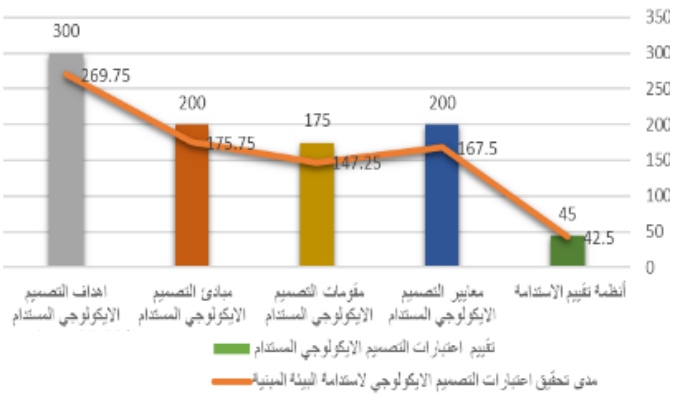

شكا ، (39) مقانة تقند تطسة , اعتارات التصمد الأكه لهح . الاكوالوجم-7-4مقارنة لترتيب العينات لمدى تطبيق اعتبارات التصميم الايكولوجي وتحقيق استدامة البيئة المبنية. تم ترتيب العينات من حيث أكبر قيمة الى الأقل، وتمثلت المرتبة المبتة

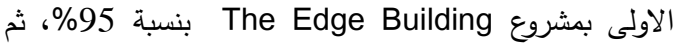

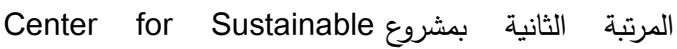
Landscapes

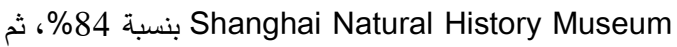

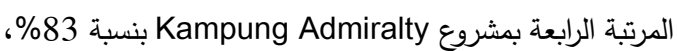

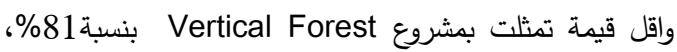
تأكيداً لتحقيق اعتبارات التصميم الايكولوجي لاستدامة البيئة المبنية لمواجهة المتغيرات المستقبلية، شكل (40).

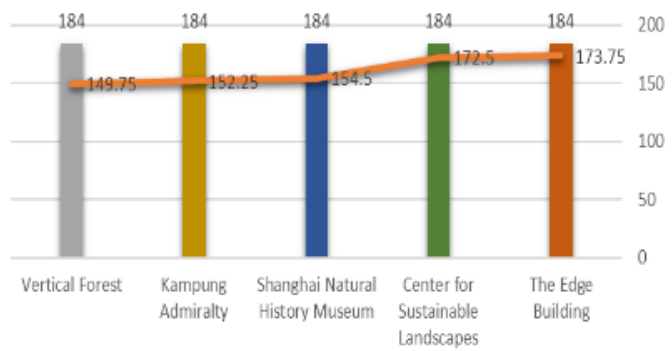

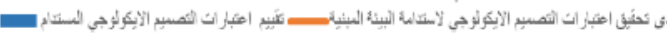
شكل (40) مقارنة ترتيب العينات حسب تحقيق المنهجية المقترحة.

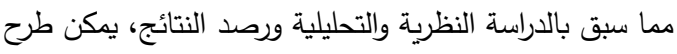

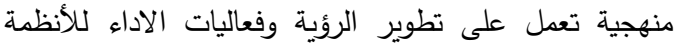

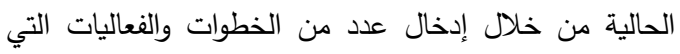
تسمح بالتطور في ظل رؤية جديدة ايكولوجية للتصميم المستدام لمواجهة القضايا البيئية والعمرانية والمتغيرات المستقبلية. 
1-يساعد التصميم الايكولوجي المستدام بأبعاده البيئية

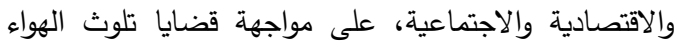

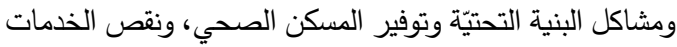

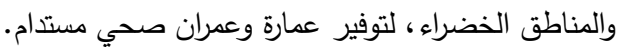

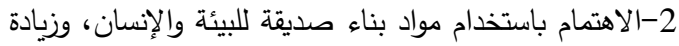
المسطح الاخضر للتخلص الجزر الحرارية وإنتاج الأكسيجين. 3-تقليل الحاجة إلى الطاقة خلال ملائمة التصميم الايكولوجي الإني

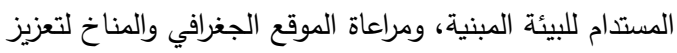

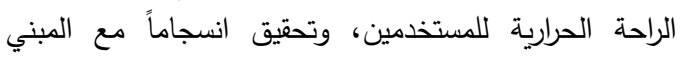
ومحيطه سواء كان طبيعياً أو من صنع الإنسان.

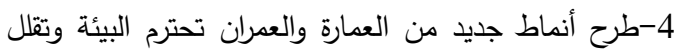

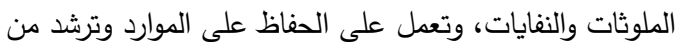

استهلاكها واستخدامها وتدويرها لتحقيق الاستدامة.

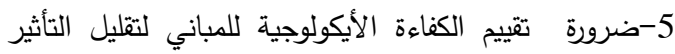

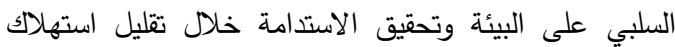

المصادر غير المتجددة وتعزيز البيئة الطبيعية. 6-تفعيل دور انظمة التقييم الدولية والاقليمية والمحلية لقياس الطئية توافق البيئة المبنية للاعتبارات الأيكولوجية وتحقيقها للاستدامة وفق إستراتيجية علمية لمنح شهادات الاعتماد لكفاءة المباني.

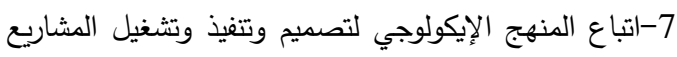

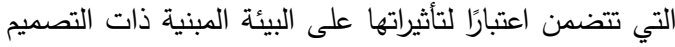

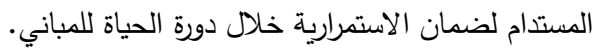
8-زيادة الوعي لاى خبراء البيئة والعمران بالاعتبارات

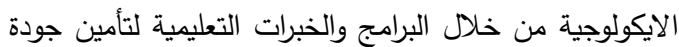
البيئة المبنية وزيادة الكفاءة التشغيلية لتحسين الصحة ولئرات العامة.

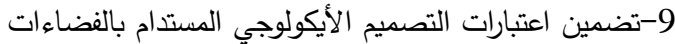

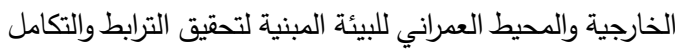

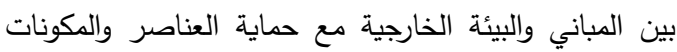
الايكولوجية الطبيعية المحيطة بالعمران. 10- زيادة الاهتمام بدور الفراغات الايكولوجي وجودة البئية البئية الداخلية لتحقيق التوازن البيولوجي بين البيئة المبنية والنظم

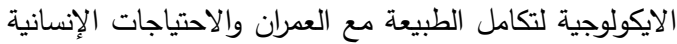

مع تقليل البصمة البيئية للأنشطة والاستخدامات البكات البشرية.

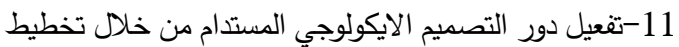

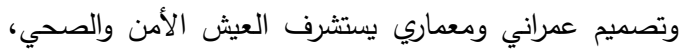

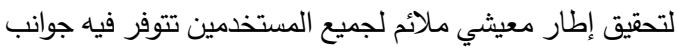
الراحة الايكولوجية وجودة الحياة المستدامة بالبيئة المبنية.
1- يحقق التصميم الأيكولوجي المستدام إيجابية العلاقة والتفاعل

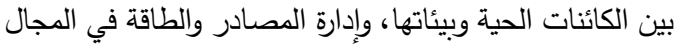

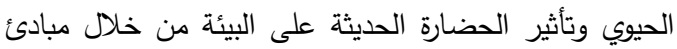
المنع والحفاظ والاسترجاع لاستدامة البيئة المبنية.

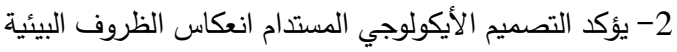

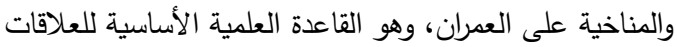
الوظيفية المتكاملة بين البيئة المبنية والعمران المستدام.

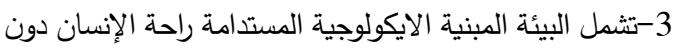
تلوث الأرض والحفاظ عليها صحية في الحاضر والمستقبل.

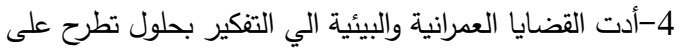

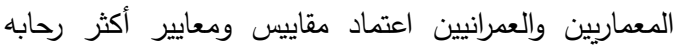

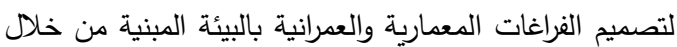
تطبيق اعتبارات التصميم الأيكولوجي المستدام.

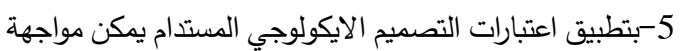

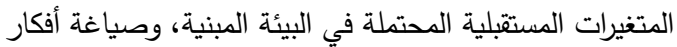

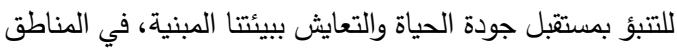
6العمرانية مع الحفاظ على المكونات والعناصر الطبيعية. 6-أثرت القضايا البيئية والعمرانية على الحئية الحياة الاجتماعية

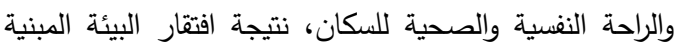

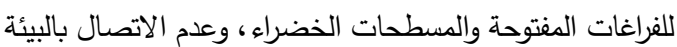
الخارجية والتفاعل مع النظم الايكولوجية بالعمران.

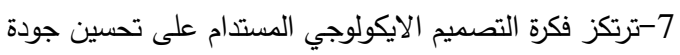

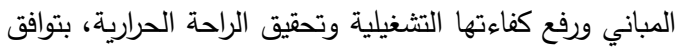

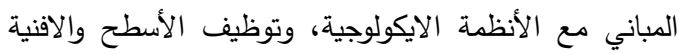

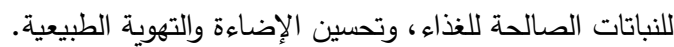

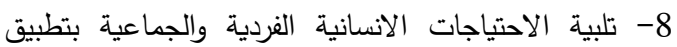

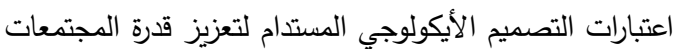
على التكيف مع البيئة المبنية والحد من التأثيرات السلبية.

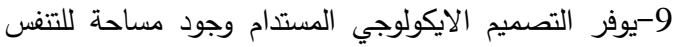
والتجمع في البيئة المبنية، مع فراغات للأطفال والثباب وكبار الإني السن، لتقوية الروابط الاجتماعية، وممارسة الأنثطة.

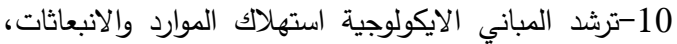

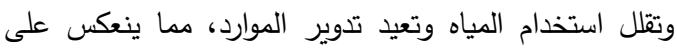
العوامل الاقتصادية والبيئية وتحقيق الاستدامة العمرانية.

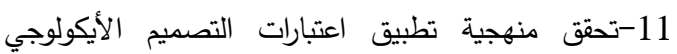

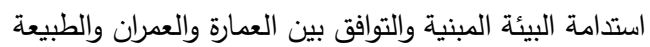
وتطرح حلواً ايكولوجية للقضايا والمتغيرات المستقبلية. 
12. Roaf, Sue, "Eco house: A Design Guide", Architectural Press, And Print of ButterworthHeinemann, 2018 p1.

13. Zhang, Guoliang, "The Emphasis on Ecological Design for High-rise Buildings", Renewable Energy Resources and A Greener Future, Vol. VIII-4-4, Shenzhen, China, 2016 .p1-3. 14. نجم، حسـين طه، "البيئة والانسـان، "دراسـات في الايكولوجيا

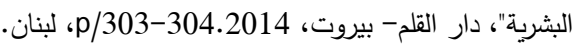

15. Berge, Bjorn, "The Ecology of Building Materials", Translated by Filip Henley, Architectural Press And print of ButterworthHeinemann, 2014 p3.

16. Roaf, Sue, "Eco house: A Design Guide", Architectural Press, And Print of ButterworthHeinemann, 2015.p224.

17. Kim, Jong-Jin; Rigdon, Brenda, "Sustainable Architecture Module: Introduction to Sustainable Design", National Pollution Prevention Center for Higher Education, 2018.p20-16.

18. الجميلي، مظفر، "أثر الخصائص التصميمية للأبنية الصناعية

على استهلاك الطاقة"، رسالة ماجستير، الجامعة التكنولوجية -

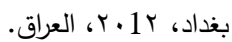

19. Zhang, Guoliang, "The Emphasis on Ecological Design for High-rise Buildings", Renewable Energy Resources and A Greener Future, Vol. VIII- 4-4, Shenzhen, China, 2016.

20. Langston, Greig, "Promoting the Reuse and Recycling of Building Demolition Materials", World Transaction on Engineering and Technology Education, Vols. No.1, 2018 p/195

21. Berge, Bjorn, "The Ecology of Building Materials", Translated by Filip 1-Henley, Architectural Press and print of ButterworthHeinemann, 2001,p14-15.
1. وحدة جهاز شئون البيئة التابع لوزارة الدولة لشئون البيئة،" تقرير حالة البيئة في مصـر"، المؤشـرات والتقارير البيئية التابع لجهاز شئون البيئة- القاهرة،2019، مصر مصن

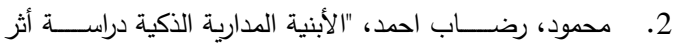
التكـامـل البيئي"، التقني في تقليـل تكلفــة المبنى الإنشــــــائيـة

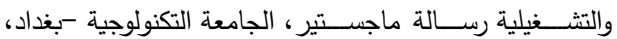
2019، العراق.

3. Yeang, K., "Design with Nature: The ecological basis for architectural design", McGraw-Hill, Inc., 2015.p/6

4. Dinur, B., "What Can Architecture Learn from Ecological System", paper,2013. p/2.

5. Roaf, Sue, "Eco house: A Design Guide", Architectural Press, And Print of ButterworthHeinemann, 2017. p/11

6. عقبة، إيهاب محمود، "مداخل التصــميم البيئي نحو التوافق مع . تغيرات البيئة الطبيعية"، المؤتمر العلمي الثالث، توفيق العمارة والعمران في عقود التحولات، كلية الهندســــة، جامعـة القاهرة 2006، مصر • (مان.

7. جاسـم، كامل، "مقدمة في علم التبيؤ البثـري"، بيت الحكمة -

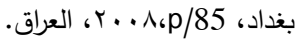

8. عمر ، مايسـة محمود فتحي، أبو العينين، أسـامة "دور المخطط

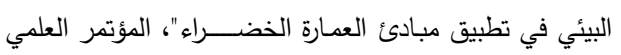
الأول، العمارة والعمران في إطار التنمية، كلية الهندسة، جامعة

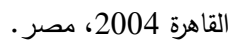

9. Richards, Ivor, "Ecology of The Sky", The Image Publishing Group, 2011.p/6-12

10. عقبة، إيهاب محمود، "استغلال تكنولوجيا الطاقة الثـمسية في

عمارة التجمعات العمرانية الجديدة كمدخل نحو عمارة مصــرية خضـــراء"، مؤتمر الأزهر الهندســـي الدولي الثامن، القاهرة، 2004، مصر . 11. فرج، أســــامة محمد علي، العطار ، محمد عصـــــ، "الدور الدلالي للتصميم البيئي في علاقة المعمار بالمعمور"، (المنظور البيئي للتتمية المســـامة في تصــميم المباني غير الســكنية)، المؤتمر العلمي الأول، العمارة والعمران في إطار التتمية، كلية الهندة، جامعة القاهرة 2004، مصر • 
34. https://www.gsa.gov/real-estate/designconstruction/designexcellence/sustainability/sus tainable-design, accessed 28/6/2020.

35. https://www.eesi.org/, accessed 22/7/2020.

36. https://arabic.cnn.com/health/article/2020/07/1 2/activities-coronavirus-texas-medicalassociation, accessed 14/7/2020.

37. https://www.worldgbc.org/benefits-green, accessed $11 / 7 / 2020$.

38. https://www.archdaily.com/.../center-forsustainable-landscap, accessed 21/7/2020.

39. https://www.archdaily.com/780979/butterflyaviary-3deluxe, accessed 23/6/2020.

40. LEEDforNewConstructionVersion2.

2ReferenceGuide.U.S.GreenBuilding

Council,p.123.Seealso,WaterResourcesResear chCentercals.arizona.edu/AZWATER/publicatio ns/sustainability/report,accessed 4/6/2020.

41. EnvironmentalHealthCenter.Formaldehyde.nsc. org/EHC/indoor/formald.htm.Seealso,

U.S.DepartmentofLaborosha.gov/SLTC/.htmlhe rmanmiller.com/ Product, accessed 30/6/2020.

42. https://www.hisour.com/ar/environmentalengineering, accessed 16/9/2020.

43. https://www.carolina.com/ resources ecology ,accessed 16/9/2020.

44. https://ara.architecturaldesignschool.com, accessed 16/9/2020.

45. https://www.archdaily.com/938222/ha-long, accessed 16/9/2020.

46. https://openhouselondon.opencityorguk/ listings, accessed 17/9/2020.

47. https://urbanmilwaukee.com/content/eco design, accessed 17/9/2020.

48. https://www.arch2o.com//architecture/ecohous, accessed 17/9/2020.

49. https://arabic.euronews.com/unprecedented-ozone, accessed 17/9/2020.
22. Leslie Dietz, Patrick F. Hove, David A. Coil, Mark Frets, Jonathan A. Eisen, Kevin Van Den Meulenberg, Built Environment Considerations To Reduce Transmission, Novel Coronavirus (COVID-19) Pandemic,2020.

23. Leslie Dietz, Patrick F. Horve, David A. Coil, Mark Fretz, Jonathan A. Eisen, Kevin Van Den , Novel Coronavirus (COVID-19) Pandemic: Built Environment Considerations To Reduce Transmission, Meulenberg, , DOI: 10.1128/mSystems.00245-20, 2020.

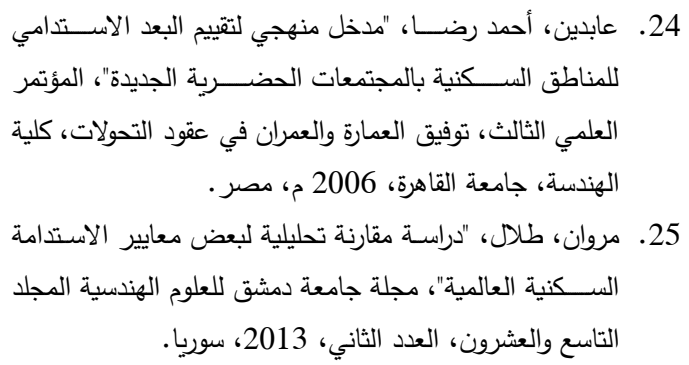

26. https://contextbd.com/pandemicpreparedness-built-environment-lessonslearned-covid-19/,lasst, accessed 2/6/2020.

27. https://contextbd.com/effect-green-buildingpandemic-prevention-2nd-position-arcasiaidea-competition/, accessed 9/6/2020.

28. https://www.bloomberg.com/.../2015-theedge-the-worlds-green, accessed 15/6/2020.

29. https://arabic.arabianbusiness.com/gallery/201 7/feb/14/432969, accessed 25/6/2020.

30. http://www.arch2o.com/oxygen-eco-towerprogetto-cmr/, accessed 20/7/2020.

31. http://www.skyscrapercenter.com/building/kam pung-admiralty/34509, accessed 10/7/2020.

32. https://www.architectmagazine.com/design/sha nghai-natural-history-museum-wins-archmadness_o, accessed 12/7/2020.

33. https://arabic.euronews.com/2020/04/24/unpre cedented-ozone-hole-in-northernhemispherecloseseno, accessed 18/7/2020. 


\title{
Assessment of Sustainable Ecological Design Considerations in the Built Environment
}

\begin{abstract}
:
In view of the multiplicity of urban problems and issues as a result of some environmental variables and the loss of diversity and biological balance in urbanization, the need arose to provide a positive relationship between buildings and the surrounding natural environment, to reduce the negative impacts on the built environment to become livable and human-friendly, as the problem was the neglect of many urbanists and architects. the application of sustainable ecological design considerations in the built environment, which led to the emergence of sick buildings with a rate of $30 \%$ of the urbanization as a result of lack of ecological integration, which included the negative aspects that the built environment suffers from at the level of buildings and surrounding spaces, and the current urban and architectural patterns to achieve the principles and standards of sustainability therefore, the research aims to assess the extent of application of ecological considerations by proposing a methodology for evaluation according to scientific foundations and standards, to find innovative mechanisms and solutions for a sustainable ecological built environment that achieve compatibility between human needs and natural, environmental determinants, in order to provide a healthy built environment to face urban issues and future variables, and the research assumes that ecological design the sustainable generation as one of the modern trends of urban and architectural thought achieves the positive relationship between buildings and the natural environment, with the achievement of production, low cost, affordability, sustainability, integration with the environment solubility, and used the inductive approach with theoretical study, and the analytical, deductive and comparative method of analytical study, to study global experiences and evaluate The validity of the proposed methodology, and then monitoring and analyzing the results in the form of graphical comparisons, which proved the validity of the hypothesis and achieving the goal by evaluating the extent of application of the proposed methodology to achieve the ecological design considerations for the sustainability of the built environment.
\end{abstract}

Keywords:

Ecological design - the built environment - sustainable urbanization - future changes - urban issues. 